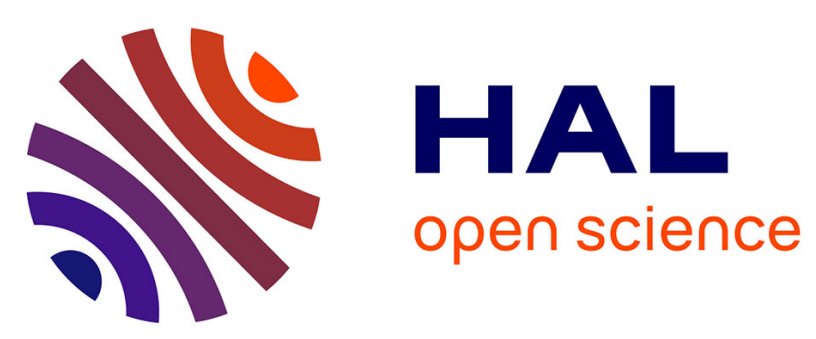

\title{
Oncological ward wastewater treatment by membrane bioreactor: Acclimation feasibility and pharmaceuticals removal performances
}

Pierre Hamon, Philippe Moulin, Lionel Ercolei, Benoit Marrot

\section{> To cite this version:}

Pierre Hamon, Philippe Moulin, Lionel Ercolei, Benoit Marrot. Oncological ward wastewater treatment by membrane bioreactor: Acclimation feasibility and pharmaceuticals removal performances. Journal of Water Process Engineering, 2018, 21, pp.9-26. 10.1016/j.jwpe.2017.11.012 hal-02114276

\section{HAL Id: hal-02114276 \\ https://hal-amu.archives-ouvertes.fr/hal-02114276}

Submitted on 29 Apr 2019

HAL is a multi-disciplinary open access archive for the deposit and dissemination of scientific research documents, whether they are published or not. The documents may come from teaching and research institutions in France or abroad, or from public or private research centers.
L'archive ouverte pluridisciplinaire HAL, est destinée au dépôt et à la diffusion de documents scientifiques de niveau recherche, publiés ou non, émanant des établissements d'enseignement et de recherche français ou étrangers, des laboratoires publics ou privés. 


\title{
Oncological ward wastewater treatment by membrane bioreactor: Acclimation feasibility and pharmaceuticals removal performances
}

\author{
P. Hamon ${ }^{\mathrm{a}, \mathrm{b}}$, P. Moulin ${ }^{\mathrm{a}, *}$, L. Ercolei ${ }^{\mathrm{b}}$, B. Marrot $^{\mathrm{a}}$ \\ a Aix Marseille Université, CNRS, Centrale Marseille, M2P2 UMR 7340, Equipe Procédés Membranaires (EPM), Europôle de l'Arbois, BP80, Pavillon Laennec, Hall C, \\ 13545 Aix en Provence Cedex, France \\ ${ }^{\text {b }}$ Société des Eaux de Marseille, 25 Rue Edouard Delanglade, 13006 Marseille, France
}

\section{A R T I C L E I N F O}

\section{Keywords:}

Pharmaceutical residues

Membrane bioreactor

Biomass acclimation

Activated sludge inhibition

Hospital wastewater

\begin{abstract}
A B S T R A C T
Discharges of care, analyses and research activities from hospital wards are the source of the specificity of hospital effluents because they contain, among others, drug residues, detergents and disinfectants. Even if hospitals represent a small fraction of the total drug load discharged into the environment, below $10 \%$ for drugs, the characterization of this specific effluent shows that global pollution is 2-3 times more concentrated than urban wastewater. Moreover this ratio increases to 150 times for some micropollutants. Activated sludge acclimation in 2 membrane bioreactor (MBR) configurations (external and external submerged) to effluents from an oncological ward will be studied monitoring the performances on conventional pollution parameters (chemical oxygen demand, ammonium, total suspended solids etc.). The performances of drug degradation are compared with the data of the literature and with degradation tests in batch reactor with no acclimated biomass from a municipal wastewater treatment plant. The results are achieved for effluents with a high concentration of drug molecules, up to $6.82 \mathrm{mg} \mathrm{L}^{-1}$ for ifosfamide. The treatment allows the development of enhanced purification efficiencies on drug molecules and confirms the choice of a MBR process to treat this effluent, although the simultaneous presence of the various compounds leads to a complex biological response. Indeed, 5-FU was eliminated almost systematically over $90 \%$. Sulfamethoxazole and codeine can be significantly eliminated biologically, respectively to 79 and 95\%. IF and CP removal in the reactor appeared more moderate since it does not exceed $40 \%$ but membrane fouling led to higher removals of both molecules.
\end{abstract}

\section{Introduction}

The problem of drug residues in the environment is global and affects all segments as pharmaceuticals have been detected in surface water and groundwater, wastewater, soil and sewage sludge [20,7,47]. The presence of drug residues in the environment and the subsequent transmission are considered as a negligible risk for human health [12]. However, these studies have some limitations since the therapeutic dose does not play the role of toxicological reference value and the effects of mixtures are not considered. In view of the reality of environmental contamination and the first proven effects it is necessary to develop innovative treatment methods in order to propose effective solutions [39]. However, the very important flow of wastewater to be treated represents a major brake to the optimization of the existing Waste Water Treatment Plant (WWTP) to address this pollution and to spread with an energy-efficient aspect of advanced technologies [39]. On the contrary, the directly on-site treatment of effluents potentially heavily loaded with drug residues could represent a sensible compromise. The implementation of reduced treatment units would indeed limit investment costs and treat effluents more concentrated in drug residues. Hospital WasteWaters (HWW) come from all the hospital activities and can be qualitatively divided into three categories [15,17]: (i) domestic discharges, (ii) industrial discharges (laundry, boiler rooms...) (iii) discharges of care, analyses and research activities. The latter category is the source of the specificity of hospital effluents because they contain, among others, drug residues, detergents and disinfectants. Biochemical characterization [61] shows that HWW conventional pollution is 2-3 times more concentrated than Urban Waste Water (UWW) and the variability of concentrations is very important according to hospitals. The patient related pollution is therefore about twice more than the inhabitant equivalent pollution. Microbiological characterization $[18,27]$ shows that bacteria in HWW are more resistant to antibiotics than those in UWW. Micropollutant pollution average concentrations in HWW are from 2 to 150 times higher than in UWW depending on micropollutants [62]. The highest ratios primarily involve antibiotics and analgesics. Orias and Perrodin [45] point out their great complexity

\footnotetext{
* Corresponding author.

E-mail address: philippe.moulin@univ-amu.fr (P. Moulin).
} 


\section{Nomenclature}

List of symbols

HWW hospital wastewater

MWW municipal wastewater

COD chemical oxygen demand

$\mathrm{COD}_{\mathrm{S}}$ supernatant chemical oxygen demand

$\mathrm{COD}_{\mathrm{P}} \quad$ Permeate chemical oxygen demand
MLVSS mixed liquor volatile suspended solids

F/M food to microorganisms ratio

TSS total Suspended Solids

eMBR external membrane bioreactor

sMBRe external submerged membrane bioreactor

WWTP wastewater treatment plant

$\mathrm{RR} \quad$ retention rate

MIC minimum Inhibitory Concentration

MWCO molecular weight cut off with significant qualitative and quantitative changes indicating that the HWW ecotoxicity strongly depends on the individual case. Hospitals represent a small fraction of the total drug load, below $10 \%$ for most drugs and even less than $3 \%$ for some of them, whereas they are generally considered as a strategic objective to reduce emissions $[62,52,39]$. However, the contribution of hospitals in UWW varies considerably according to drugs. [62] note that between 16 and $67 \%$ of 12 analyzed drugs out of 73 in UWW come from HWW. Santos et al. [52] indicate in their study that analgesics, antibiotics and non-steroidal anti-inflammatory drugs are the 3 major classes brought by hospitals in UWW with a rate of up to $50 \%$.

Some activities of hospitals produce very specific pollutants that could be interesting to treat directly by implementing small treatment units directly on-site [37,28,58,69,33,3]. [38] Orias and Perrodin [45] also note that little attention was paid so far to antineoplastic drugs during studies about HWW ecotoxicological risks despite "highest concentration measured in waste water/predicted non-effect concentration" high ratios (244,000 for fluorouracil).

The presence of drug residues and their metabolites in the environment involves that they are not completely eliminated by conventional wastewater treatment plants (WWTP) with activated sludge. The sludge age appears to be the key parameter to eliminate micropollutants by activated sludge processes $[8,43]$. The almost total biomass retention in the membrane bioreactor (MBR) process helps to work on a sludge age much higher than in WWTPs with conventional activated sludge. Sipma et al [55] compared the performances of conventional WWTPs with the performances of membrane bioreactors: only three molecules (solatol, famotidine, hydrochlorotiazide) out of the 30 selected drugs were better eliminated by conventional WWTPs than by MBRs. The reduction of the 27 other molecules was either similar or better by MBR, although it should be noted that some molecules remain poorly removed. For poorly biodegradable, polar and persistent micropollutants such as most of the pharmaceutical molecules, several studies indicate that better eliminations are obtained with MBR [13,4,49,50,32].

It is noteworthy that for identical Sludge Residence Time (SRT) similar reductions were achieved by MBR and conventional WWTPs on various micropollutants confirming the major role of SRT in the reduction of micropollutants Clara et al., 2004. Therefore, the major advantage of MBR seems to be the capability to define SRT independently from Hydraulic Residence Time (HRT). Tambosi et al. [59] confirmed the role of SRT obtaining a better removal of 6 pharmaceutical molecules by increasing the SRT from 15 to 30 days in a MBR. As a consequence, a high SRT maintains a metabolic potential when a particular substrate is no longer in the effluent. MBR thus has a "memory effect" and is therefore more flexible during important fluctuations in concentrations [13].

Few studies have been devoted to the treatment of effluents from a specific hospital department by MBR. In addition, most of the studies on specific anticancer drugs have been carried out with synthetic effluents $[14,54]$ composed of few pharmaceuticals. The originality of this study is to test the treatment feasibility of a real effluent directly on site of an oncological ward by MBR. The biomass acclimation to effluents from a department of oncology is thus studied following the MBR performances on conventional pollution parameters (COD, SOUR, Ammonium, etc.) as well as the evolution of Total Suspended Solids (TSS) in the bioreactor. The acclimation to oncological ward effluent will be compared for two different MBR configurations: external membrane (eMBR) and external submerged membranes (sMBRe). The results are achieved for effluents with very heavy drug concentrations.

\section{Materials \& methods}

\subsection{Compounds, follow-up and analysis}

The 3 most consumed anticancer drugs in the unit of the department of oncology of the hospital La Timone (Marseille, France) belong to the 7 anticancer treatments listed by the AFFSA (French Food Safety Agency): ifosfamide (IF), fluorouracile (5-FU), cyclophosphamide (CP). The codeine painkiller (CD) and the sulfamethoxazole antibiotic (SM) were added to the list of medicines taken for the project. According to their physical and chemical properties the major anticancer drugs seem mostly persistent with a high mobility in water $[33,68]$. This is true for 5-FU, CP and IF but also for CD and SM. The very low values of the water-octanol partition coefficient $\mathrm{K}_{\mathrm{ow}}$ of the 5 selected drugs indicate that these molecules are slightly hydrophobic and strongly polar. The fluorouracil analyses are carried out in the laboratory of pharmacology and toxic kinetics from the hospital la Timone in Marseille (France). The cyclophosphamide, ifosfamide, codeine, and sulfamethoxazole analyses were conducted by the Ianesco laboratory (Institut d'Analyses et d'Essais en Chimie de l'Ouest) from Poitiers. The protocol for dosing 5-FU in blood plasma was successfully used for dosing in hospital effluents and treated waters. 5-FU analysis is performed via HPLC-UV. The quantification limit is $5 \mu \mathrm{g} \mathrm{L}{ }^{-1}$. The four other molecules i.e. cyclophosphamide, ifosfamide, sulfamethoxazole, and codeine are analyzed simultaneously via liquid chromatography together with a mass spectrometry (LC/MS-MS). The quantification limit of the analysis is $2.5 \mu \mathrm{g} \mathrm{L}^{-1}$. Raw waters are settled then filtered on a filter with a porosity of $0.45 \mu \mathrm{m}$ before analysis. The elimination of the coarser solids is not a priori a problem of underestimation of the concentration of drugs in HWW since the selected drugs are excreted only through urine and are hydrophilic thereby neglecting the sorption on the TSS of HWW.

\subsection{Hospital wastewaters}

The studied effluents come from oncology ward at the hospital La Timone (Marseille, France). The pipe collects wastewater (sink, shower, toilets) of 6 rooms without being diluted by the other activities of the ward. Oncological ward wastewater (HWW) is batch sampled and gathered in a buffer vessel. Pretreatments consist of a saniflo macerator system (Plus Silence, SFA, France) and a grid with a $0.5 \mathrm{~mm}$ cutoff. The sampling is performed in the morning in order to have an effluent loaded enough to ensure a minimum food to microorganism ratio $(\mathrm{F} / \mathrm{M})$ of $0.07 \mathrm{~kg}_{\mathrm{COD}} \mathrm{kg}_{\mathrm{VSs}}{ }^{-1} \mathrm{~d}^{-1}$ corresponding to the operating boundary conditions chosen regularly for urban effluents [23]. The related F/M ratio always lies between 0.07 and $0.14 \mathrm{~kg}_{\mathrm{COD}} \mathrm{kg}_{\mathrm{vss}}{ }^{-1} \mathrm{~d}^{-1}$. The $\mathrm{BOD}_{5} /$ COD ratio shows that the effluent is biodegradable because it is relatively steady between 29 and $48 \%$. These 160 days long campaign has 


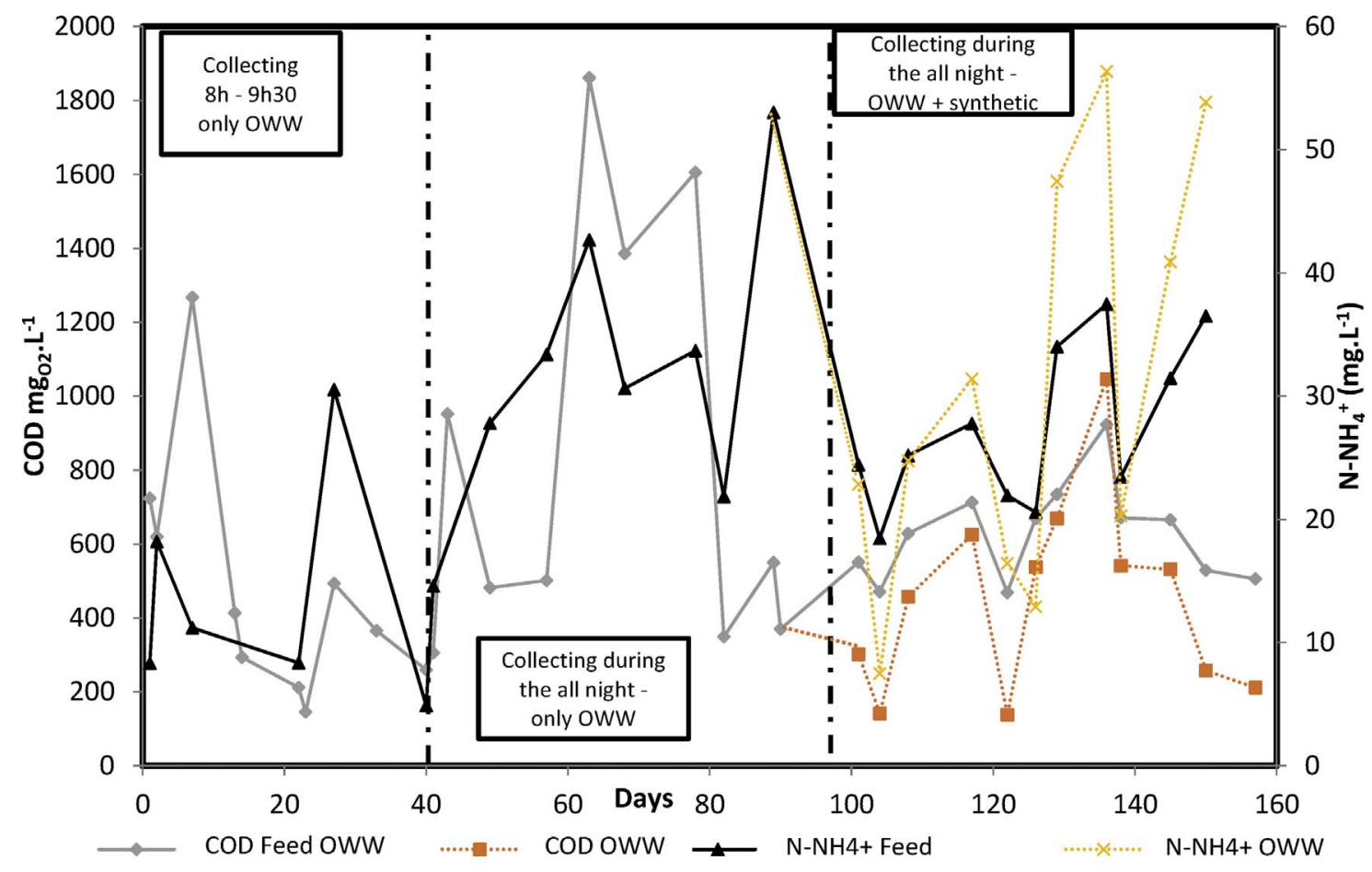

Fig. 1. Evolution of COD and ammonia in OWW during the 1st experimental campaign (eMBR).

two distinct phases because it was decided to co-supply the eMBR with a synthetic substrate at the 97th operating day. The evolutions of carbon pollution (COD) and nitrogen pollution $\left(\mathrm{N}^{-\mathrm{NH}_{4}}{ }^{+}\right)$of $\mathrm{HWW}$ during the first experimental campaign have fluctuated considerably (Fig. 1).

3 working conditions can be considered:

- 0 to 40th day: HWW sampling between 8:00 and 9:30 am;

- 40th to 97th day: HWW sampling during the night to avoid dilution via shower waters;

- 97th to 160th day: co-supply with HWW and a synthetic substrate to help acclimation.

On the 40th day, the change of sampling method led to an effluent more loaded in ammonium. On the 97th day the synthetic substrate brought a relative stabilization in COD and $\mathrm{N}_{-} \mathrm{NH}_{4}{ }^{+}$concentrations. Despite the standardization of the sampling method from the 40th day, important fluctuations in COD and $\mathrm{N}_{-} \mathrm{NH}_{4}{ }^{+}$concentrations have been identified, which may indicate a certain heterogeneity in the activity of Oncology ward. The composition of the synthetic substrate to dilute the specific pollution load of the HWW from the 97th day has been determined from the average COD $\left(800 \mathrm{mg} \mathrm{L}^{-1}\right)$ and $\mathrm{N}-\mathrm{NH}_{4}^{+}$ (31 $\mathrm{mg} \mathrm{L}^{-1}$ ) concentrations measured during the period from the 40th to the 97th day (Table 1). Concentrations in mineral salts are determined by the literature $[26,2]$. The $\mathrm{C} / \mathrm{N} / \mathrm{P}$ ratio of the synthetic effluent is $100 / 4 / 2$ with $\mathrm{C}$ corresponding to organic carbon. In this synthetic wastewater the concentration of $\mathrm{C}_{6} \mathrm{H}_{12} \mathrm{O}_{6},\left(\mathrm{NH}_{4}\right)_{2} \mathrm{SO}_{4}, \mathrm{MgSO}_{4}$, $\mathrm{KH}_{2} \mathrm{PO}_{4}$ and $\mathrm{CaCL}_{2}$ are respectively $800 ; 146,7 ; 38,1 ; 76,2$ and $7,6 \mathrm{mg} \mathrm{L}^{-1}$. On the 40th day, the change in the sampling method led to harmonize the supply $\mathrm{C} / \mathrm{N}$ ratio reasonably between 15 and 50 . The synthetic substrate added on the 97th day has increased this stabilization around 25 and then allows the compensation for the continuous fluctuations of the HWW C/N ratio.

\subsection{Membrane bioreactor}

A pilot scale membrane bioreactor was dimensioned, built and implemented nearby in the oncology ward at the hospital La Timone
(Marseille, France) (Fig. 2). The pilot MBR dimensioning was based on a permeate flow rate included between 1 and $2 \mathrm{~L} \mathrm{~h}^{-1}$. The pilot allows an easy change of configuration from eMBR to sMBRe by simply reversing the membrane module then the connections to the suction pump and to air injection. The pilot has a maximum capacity of $60 \mathrm{~L}$, the work volume has been set to $32 \mathrm{~L}$. A $3.1 \mathrm{~kW}$ cold unit regulates the temperature of activated sludge at $25 \pm 2{ }^{\circ} \mathrm{C}$ via 2 exchangers placed at the recirculation loops of both biological tanks. HWW are contained in a storage tank of maximum $200 \mathrm{~L}$ and are renewed every two days. At first, HWW are sent in the denitrification tank $(10.5 \mathrm{~L})$ by the feed pump enslaved to level rods. The tank is stirred by a recirculation of sludge by a peristaltic pump. The bacterial flocs are kept in suspension while avoiding the aeration of the anoxic zone allowing the denitrification reaction. A part of the recirculate sludge is transferred to the aerobic tank with a $21.5 \mathrm{~L}$ sensitive volume, where the nitrification reaction occurs. Hydraulic residence time (HRT) in both tanks is ensured by setting valves V6 and V7 to perform $1 \mathrm{~h} / 2 \mathrm{~h}$ cycles in the anoxic and aerobic tanks respectively. The flow of the transferred sludge was controlled by reading the magnetic flow meter $\mathrm{FI}_{1}$ (Proline Promag 10H, Endress Hauser). A fine bubbles aeration is produced by four porous powered by a compressor. It maintains the oxygen concentration above $2 \mathrm{mg} \mathrm{L}^{-1}$ and helps stirring the aerobic tank. The air flow is controlled by a ball flow meter $\left(0-800 \mathrm{NL} \mathrm{h}^{-1}\right.$, DK37, Khrone). A centrifugal pump low pressurizes activated sludge at the bottom of the nitrification tank towards the membrane module (B3, Motovario). The circulation conditions of the sludge within the membrane module depend on the MBR configuration. For the eMBR configuration the circuit is under 2 bar pressure approximately. A tangential velocity about $4 \mathrm{~m} \mathrm{~s}^{-1}$ is imposed in the membrane (Membrane Carbosep M1, $150 \mathrm{kDa}, \mathrm{ZrO}_{2}-\mathrm{TiO}_{2}$ ). This velocity is set by the $\mathrm{V} 15$ valve and by reading the sludge recirculation flow on the magnetic flow meter $\mathrm{FI}_{2}$ (Proline Promag 10H, Endress Hauser). A back pressure micrometric valve (V18) at the permeate outlet adjusts the permeate flow very precisely. For the sMBRe configuration the sludge recirculation velocity is very low compared to the external configuration. Frequency of the peristaltic pump increases with acclimation to compensate the gradual decrease of permeability due to the fouling of hollow fibers (Polymem, M2; Polysulfone $100 \mathrm{kDa}$ ). Compressed air is injected under the form of 
Table 1

Ratio of maximal concentrations detected in OWW, HWW and MWW (sMBRe).

\begin{tabular}{|c|c|c|c|c|c|c|c|}
\hline Molecule & {$\left[O W W_{\max }\right]_{\text {presentstudy }}$} & & {$\left[H W W_{\text {max }}\right]$ litterature } & {$\left[O W W_{\max }\right]_{\text {presentstudy }}$} & & {$\left[M W W_{\max }\right]$ litterature } & {$\left[O W W_{\max }\right]_{\text {presentstudy }}$} \\
\hline $\mathrm{CP}$ & 687 & 5.73 & Gomez-Canela et al. [22] & 120 & 0.143 & Steger-Hartmann et al. [57] & 4804 \\
\hline IF & 6820 & 10.647 & Yin et al. [66] & 640 & 0.029 & Kümmerer et al. [36] & 235172 \\
\hline SM & 710 & 4.588 & Kovalova et al. [34] & 155 & 7.91 & Peng et al. [46] & 90 \\
\hline $\mathrm{CD}$ & 47 & 50 & Foster [19] & 0.9 & 32.295 & Kasprzyk-Hordern et al. [31] & 1.5 \\
\hline
\end{tabular}

Concentrations are expressed in $\mu \mathrm{g} \mathrm{L}^{-1}$.

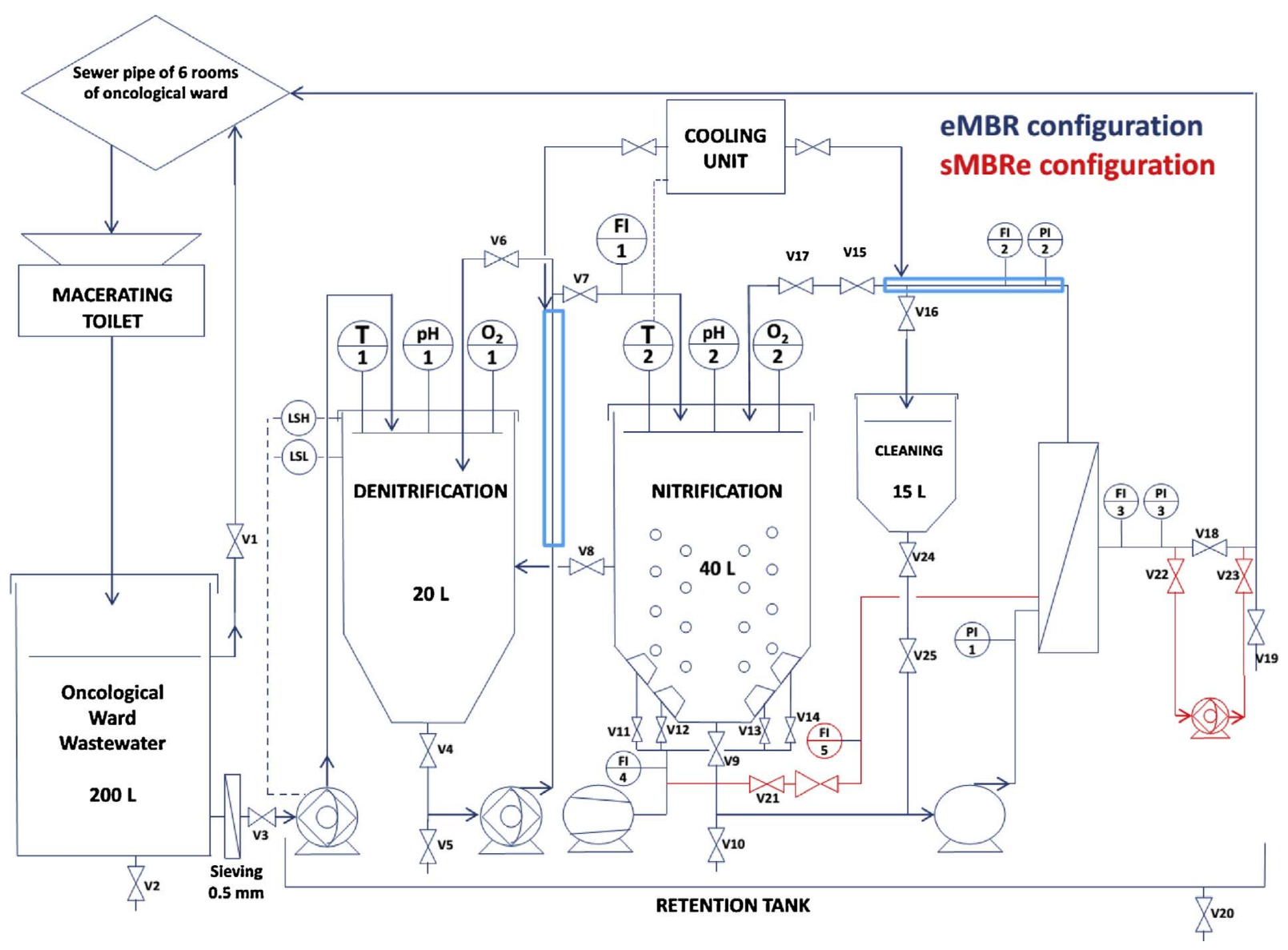

Fig. 2. PID of the MBR pilot.

bubbles in order to limit the fouling by shearing. A flow meter controls the air flow at $9 \mathrm{~L} \mathrm{~min}^{-1}\left(7.5 \mathrm{~m}^{3} \mathrm{~m}^{-2} \mathrm{~h}^{-1}\right.$ for eMBR and $0.4 \mathrm{~m}^{3} \mathrm{~m}^{-2} \mathrm{~h}^{-1}$ for sMBRe). In addition, a relaxation and a backwash are performed twice a day. In both MBR configurations, the retentate is repressed in the nitrification tank while the permeate is sent in the wastewater pipe from the oncology department. The operating characteristics of both configurations are summarized in Table 2. A chemical cleaning of the membranes (recommended by the supplier) directly on the pilot is carried out when the gradual decrease of permeability due to the fouling avoids achieving a sufficient permeate flow.

\subsection{Origin of activated sludge and analyses}

The activated sludge used to inoculate the MBR comes from the municipal wastewater treatment plant (municipal MBR) in Rousset (Bouches du Rhône, France). They have been collected in a basin containing biomass successively placed in aerobic and anoxia conditions by cycles of aeration - no aeration of $10 \mathrm{~min}-40 \mathrm{~min}$. (8.2 $\mathrm{g}_{\mathrm{MES}} \mathrm{L}^{-1} \mathrm{~g}_{\mathrm{MES}} \mathrm{L}^{-1}$ for the first experimental campaign and
$6.8 \mathrm{~g}_{\mathrm{MES}} \mathrm{L}^{-1} \mathrm{~g}_{\mathrm{MES}} \cdot \mathrm{L}^{-1}$ for the second). A daily follow-up of totally suspended matters (TSS) and volatile suspended solids (VSS) concentrations is carried out to know the biomass evolution in the MBR. $\mathrm{NH}_{4}{ }^{+}$and $\mathrm{NO}_{3}{ }^{-}$are analyzed once or twice a week in HWW and in the permeate. COD is also analyzed once or twice a week in HWW, in the

Table 2

Operating conditions for both MBR configurations.

\begin{tabular}{|c|c|c|c|c|c|c|}
\hline & \multicolumn{3}{|c|}{ eMBR } & \multicolumn{3}{|c|}{ sMBRe } \\
\hline & $\min$ & $\max$ & average & $\min$ & $\max$ & average \\
\hline $\begin{array}{c}\text { Permeate flow rate } \\
\left(\mathrm{L} \mathrm{h}^{-1}\right)\end{array}$ & 1 & 2 & $1.42 \pm 0.22$ & 0.8 & 2 & $1.13 \pm 0.27$ \\
\hline $\begin{array}{c}\text { Hydraulic retention } \\
\text { time (h) }\end{array}$ & 16 & 32 & $23.0 \pm 3.6$ & 16 & 40 & $29 \pm 8$ \\
\hline $\begin{array}{c}\text { Transmembrane } \\
\text { pressure (bar) }\end{array}$ & 0.8 & 2.2 & $1.30 \pm 0.23$ & 0.06 & 0.75 & $0.39 \pm 0.18$ \\
\hline Sludge age & \multicolumn{3}{|c|}{ Infini } & \multicolumn{3}{|c|}{ Infini } \\
\hline $\begin{array}{c}\text { Aerated/not aerated } \\
\text { phases (h) }\end{array}$ & \multicolumn{3}{|c|}{$2 / 1$} & \multicolumn{3}{|c|}{$2 / 1$} \\
\hline
\end{tabular}


activated sludge supernatant and in the permeate. Permeate and sludge samples were collected the day after collecting HWW to comply with the relatively long HRT to calculate the corresponding purification yields. The sludge samples are centrifuged during $15 \mathrm{~min}$ at $13,500 \mathrm{rpm}$ (centrifuge 2-16, Sigma) then the liquid phase is filtered on a coffee filter (average pore size $100 \mu \mathrm{m}$ ) to remove all the particles. HWW COD is analyzed on the raw sample after passing through the pre-treatment grid. The solid phase resulting from centrifugation is retrieved in an aluminum plate placed in an oven (Nabertherm) at $105^{\circ} \mathrm{C}$ during $24 \mathrm{~h}$. TSS concentration is obtained from the dry matter weighing. The oven temperature is then set at $550{ }^{\circ} \mathrm{C}$ during $2 \mathrm{~h}$ to remove the organic matter and obtain the VSS concentration by weighing difference between drying at $105{ }^{\circ} \mathrm{C}$ and oven at $550^{\circ} \mathrm{C}$. The COD is analyzed with Aqua Lytic kits (20-150 mg L${ }^{-1}$, Aqual Lytic). The $\mathrm{BOD}_{5}$ is measured after 5 days (OxiTop, WTW). The $\mathrm{NH}_{4}{ }^{+}$and $\mathrm{NO}_{3}{ }^{-}$concentrations are determined with the Merck kits $\left(2-150 \mathrm{mg}_{\mathrm{N}-\mathrm{NHH} 4} \mathrm{~L}^{-1} \mathrm{mg}_{\mathrm{N}-\mathrm{NHH} 4} \mathrm{~L}^{-1}\right.$ and $0-20 \mathrm{mg}_{\mathrm{N}-\mathrm{NO} 3} \mathrm{~L}^{-1}$ ).

Antibiograms are performed during the second experimental campaign in order to assess the evolution of the biomass antibiotic-resistant properties during acclimation. The 6 most consumed antibiotics in the oncology department are selected for this follow-up. There are amoxicillin and ticarcillin penicillins, cephalosporin antibiotics of third generation ceftazidim and ceftriaxone, fluoroquinolone antibiotics ciprofloxacin and carbapenem meropenem. Antibiograms are performed according to the recommendations of the antibiogram committee of the French society of Microbiology [6]. The activated sludge is diluted with physiological water ( $9 \mathrm{~g}$ of sodium chloride by liter of distilled water) until there is a turbid suspension equal to Mc Farland 0.5 standard $\left(\sim 10^{8} \mathrm{UFC} \mathrm{mL}^{-1}\right)$. Mc Farland 0.5 standard corresponds to a 0.132 absorbance at a $600 \mathrm{~nm}$ wave length. The performed solution can then be diluted by a factor 10 or 100 according to the studied bacteria. The absence of studies about the completion of an antibiogram on activated sludge has imposed several preliminary tests. The $1 / 10$ th dilution of the turbid suspension equal to the Mc Farland 0.5 standard has been selected because it provides the "good number of bacteria/visible inhibition" compromise. Mueller-Hinton is the medium used because it is suitable for the development of Enterobacteria, staphylococci and pseudomonas and other non-fermenting negative Gram bacilli. The medium is seeded by flooding using a Pasteur pipette. The surplus is vacuumed and there is a $15 \mathrm{~min}$ air drying. With a sterilized clamp a maximum of 3 antibiotic discs are then arranged equidistant on the seeded agar. Boxes are incubated $24 \mathrm{~h}$ at $37^{\circ} \mathrm{C}$ in aerobic conditions. After incubation, inhibition diameters around antibiotics discs are measured and the minimum inhibitory concentrations (MIC) are calculated from those above and then compared with the activated sludge of the municipal WWTP from Rousset $(\mathrm{t}=0)$ to quantify the acquired antibiotic resistance. 3 antibiograms are performed for each trial to ensure the result repeatability.

\section{Results with an eMBR}

\subsection{Biomass acclimation}

The loading of the eMBR pilot was carried out with sludge from the municipal WWTP at $8.2 \mathrm{~g} \mathrm{~L}^{-1}$ concentration in TSS. Throughout the acclimation (Fig. 3a), the proportion of volatile suspended solids (VSS) in the TSS is submitted to negligible variations ( $85 \pm 3 \%$ ).

After an initial loss (Phase 1) of half of the biomass observed from the very first day after inoculation and undoubtedly due to the new conditions which the biomass undergoes between the WWTP and the MBR, a significant phase of bacterial growth is observed (phase 2) because the TSS concentration increases from $3.4 \mathrm{~g} \mathrm{~L}^{-1}$ to $5.1 \mathrm{~g} \mathrm{~L}^{-1}$ between the 14 th and the 27th day. This significant phase of biomass growth between the 14th and the 27th day could be explained by the consumption of soluble microbial products released during the cell lysis of phase 1 despite the low incoming COD. Then there is a rough drop (phase 3 ) due to a modification of the routine activity of the Oncology ward, shower and domestic waters are mainly retrieved. Surfactants (soap and cleaning products) may have disrupted mass transfers within bacterial flocs. From the 40th day, HWW are retrieved during the whole night in order to get rid of shower waters. An overflow was installed on the HWW storage tank for the continuous sampling. A $2.0 \mathrm{~g} \mathrm{~L}^{-1}$ biomass growth at the 40th day and $3.7 \mathrm{~g} \mathrm{~L}^{-1}$ at the 96th day can be noticed on phase 4. F/M peaks between the 60th and the 80th days (Fig. 3b) are due to COD peaks in the HWW obtained despite the night sampling, which allegedly harmonize HWW concentrations. This very light bacterial growth on the long term shows the difficulties of the biomass to acclimate to HWW. It is likely that the HWW, which contain a multitude of drugs with high concentration, have an inhibitory effect on the growth of activated sludge. From the 97th day, the drug load, which feeds the pilot MBR, is diluted by half with a synthetic effluent in order to buffer the incoming fluctuations and to allow the biomass to grow. Phase 5 corresponds to the operation of the MBR feeded by half with HWW and with the synthetic effluent. The first effect of the synthetic substrate intake has been the stabilization around $0.20 \mathrm{~kg}_{\mathrm{COD}} \mathrm{kg}_{\mathrm{vss}}{ }^{-1} \cdot \mathrm{d}^{-1} \mathrm{~kg}_{\mathrm{COD}} \mathrm{kg}_{\mathrm{vss}}{ }^{-1} \mathrm{~d}^{-1}$ $\left(0.20 \pm 0.05 \mathrm{~kg}_{\mathrm{COD}} \cdot \mathrm{kg}_{\mathrm{vss}}{ }^{-1} \cdot \mathrm{d}^{-1}\right)$. Despite the dilution by 2 of HWW, a lot of fluctuations have been observed again in the biomass development. Although the TSS evolution still tends towards a low growth from 36 g.L $\mathrm{L}^{-1}$ at the 97th day to $4.6 \mathrm{~g} \mathrm{~L}^{-1}$ at the 160th day, it is less pronounced than the one of phase 4 when HWW was the only substrate. The growth phase with synthetic substrate is therefore 2.7 times lower than the growth of the phase with HWW as only substrate. The slower growth can be the attributed to the average F/M 1,7 times stronger than during phase 4 $\left.\left(0.34 \mathrm{~kg}_{\mathrm{COD}} \mathrm{kg}_{\mathrm{vss}}{ }^{-1} \mathrm{~d}^{-1}\right) \mathrm{kg}_{\mathrm{COD}} \cdot \mathrm{kg}_{\mathrm{vss}}{ }^{-1} \cdot \mathrm{d}^{-1}\right)$ compared with phase 5 $\left(0.20 \mathrm{~kg}_{\mathrm{COD}} \mathrm{kg}_{\mathrm{vss}}{ }^{-1} \mathrm{~d}^{-1}\right)$. The slight biomass growth obtained on the long term means that the acclimation to HWW is possible but remains very tricky because of the effluent feature.

\subsection{Purification efficiency}

The overall reduction of COD via the MBR is always more than $90 \%$ during acclimation except at the 123rd day where a one-time drop to $86 \%$ is noticed (Fig. $3 \mathrm{~b}$ ).

The removal of $C O D$ in the permeate $\left(C O D_{P}\right)$ seems rather independent from the reduction of COD into the supernatant $\left(\mathrm{COD}_{\mathrm{S}}\right)$. The membrane $(150 \mathrm{kDa})$ is efficient on the COD retention not metabolized by bacteria. At the $23 \mathrm{rd}$ day, a $\mathrm{COD}_{\mathrm{S}}$ stronger than the HWW would confirm the attribution of the bacterial growth phase between the 14th and the 27th day to the cell lysis, which occurred during the first acclimation phase. The significant biomass growth observed between the 14th and the 27th day can be explained by the consumption of released extracellular polymers by the surviving bacteria.

Whereas the $\mathrm{COD}_{\mathrm{S}}$ removal has then increased, a gradual decrease from 81 to $43 \%$ of the COD reduction from the 43rd to the 58th day seems related to the decreases of the $\mathrm{C} / \mathrm{N}$ ratio of HWW during that period (between 15 and 21) and of the $F / M$ after a peak at $0.45 \mathrm{~kg}_{\text {COD }} \cdot \mathrm{kg}_{\mathrm{vss}}{ }^{-1} \mathrm{~d}^{-1} \mathrm{~kg}_{\mathrm{COD}} \cdot \mathrm{kg}_{\mathrm{vss}}{ }^{-1} \cdot \mathrm{d}^{-1}$ to the 43rd day. As well, another decrease has been observed at the 83rd day, linked again to drop of the $\mathrm{C} / \mathrm{N}$ ratio (from the 48 at the 78th day to 16 at the 82nd) and an important drop of $F / M$ (from $0.72 \mathrm{~kg}_{\mathrm{COD}} \mathrm{kg}_{\mathrm{vss}}{ }^{-1} \mathrm{~d}^{-1} \mathrm{~kg}_{\mathrm{COD}} \cdot \mathrm{kg}_{\mathrm{vss}}{ }^{-1} \cdot \mathrm{d}^{-1}$ at the 78 th day to $0.20 \mathrm{~kg}_{\mathrm{COD}} \cdot \mathrm{kg}_{\mathrm{vss}}{ }^{-1} \cdot \mathrm{d}^{-1} \mathrm{~kg}_{\mathrm{COD}} \cdot \mathrm{kg}_{\mathrm{vss}}{ }^{-1} \cdot \mathrm{d}^{-1}$ at the $82^{\mathrm{d}}$ day). The synthetic substrate intake at the 97th day allows the stabilization of the mass loading and of the $\mathrm{C} / \mathrm{N}$ ratio between 14 and 25 . These conditions seem to favor the elimination of organic pollution since the reduction of COD in the supernatant becomes more constant and always greater than $78 \%$ up to the end of the experimental campaign. Considering over this period an elimination of $95 \%$ of the COD easily biodegradable from the synthetic substrate, the elimination of COD from the HWW is very good, since it lies between 73 and 91\%, except occasionally at the 123rd day. This decrease would indicate that a cell lysis caused by HWW and would be confirmed by an occasional decrease of TSS at the 124th day. Only a decrease of F/M from 0.33 at the 117 th day to 0.14 at the 122 nd 


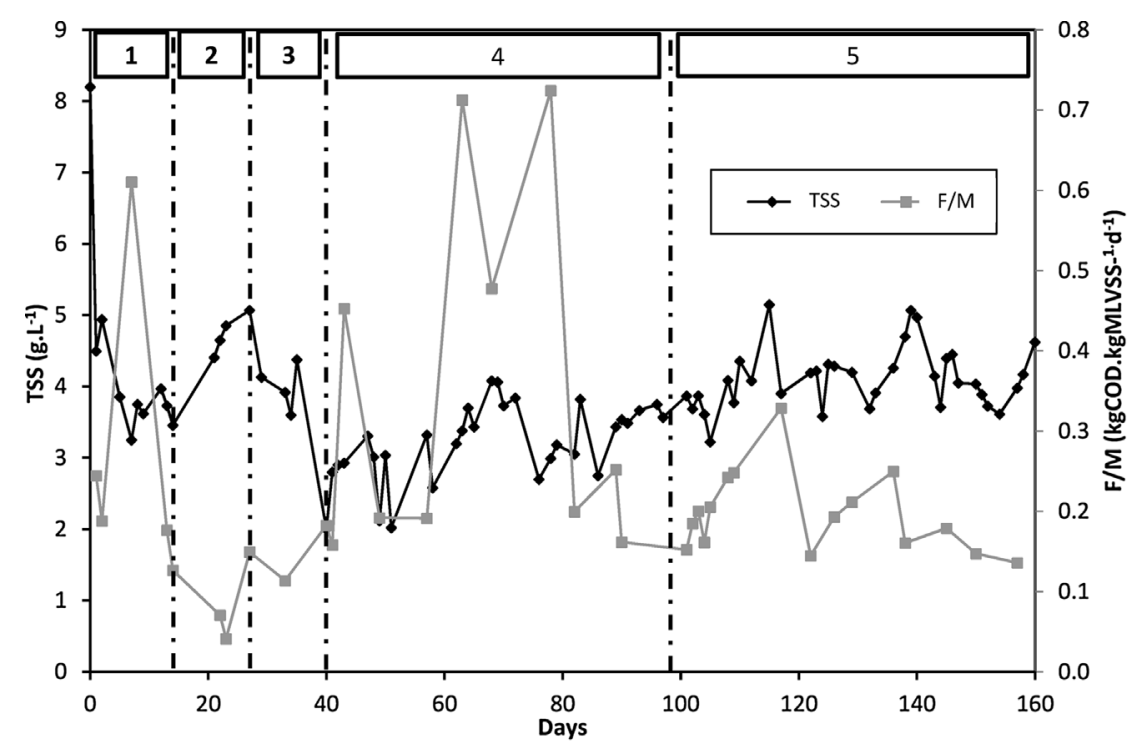

a

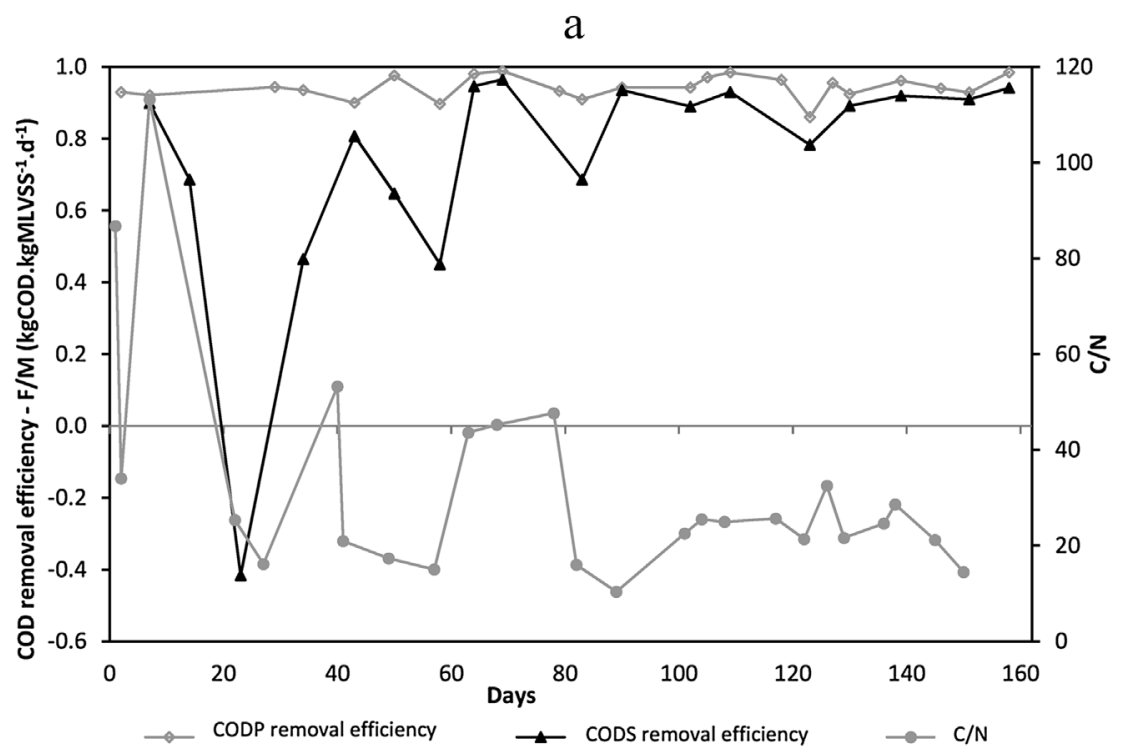

b

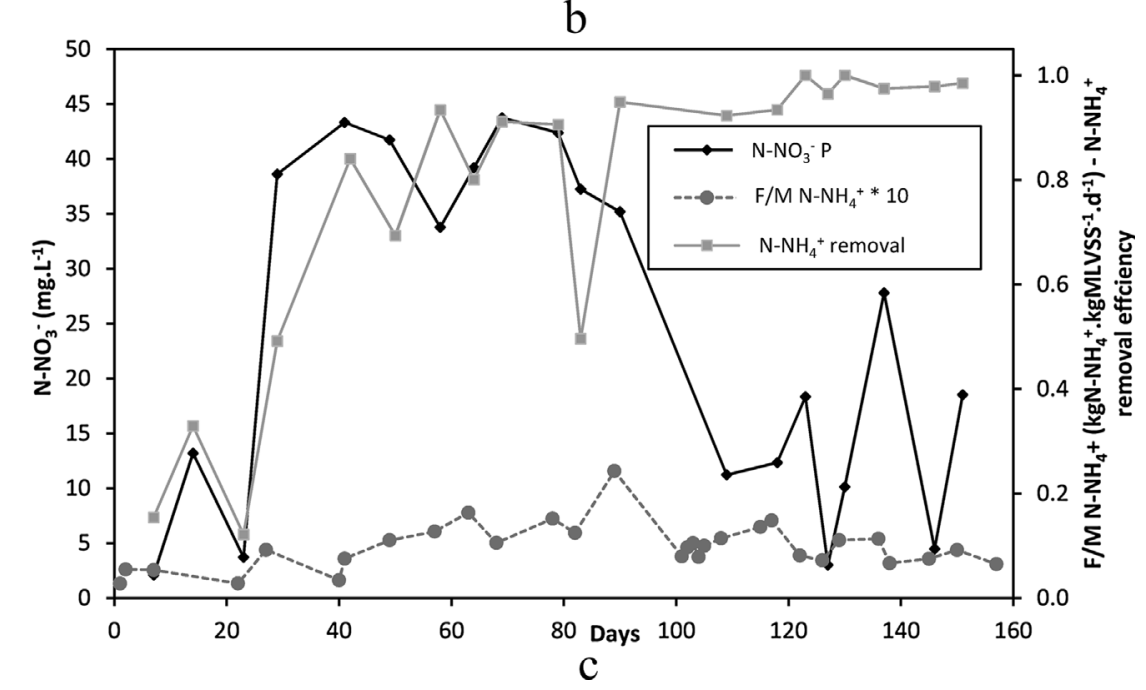

Fig. 3. Evolution of (a) TSS and the F/M ratio (eMBR) (b) the $\mathrm{C} /$ $\mathrm{N}$ ratio and COD removal efficiencies in supernatant and permeate (eMBR) (c) nitrates and ammonia removal efficiciency in permeate and the ammonia $\mathrm{F} / \mathrm{M}$ ratio during the 1st experimental campaign (eMBR) day has been noticed since the $\mathrm{C} / \mathrm{N}$ ratio is steady. The $\mathrm{F} / \mathrm{M}$ decrease is due to a lower COD concentration of HWW at the 122nd day, which would have caused an occasional loss of biomass.

The ammonium reduction seems very low at the beginning of acclimation (Fig. 3c) and then increases and stabilizes. It is however noteworthy that very occasional drops (83rd day) may come from HWW deficiencies. From the 97th day, the synthetic substrate intake stabilizes the ammonium reduction over $92 \%$ with an upward 
tendency. At the $123 \mathrm{rd}$ day, it is noteworthy that a $100 \%$ reduction of ammonium has been obtained whereas an occasional cell lysis is occurring. This cell lysis would mainly affect heterotrophic bacteria.

The reduction of ammonium seems to be mainly influenced by the fluctuations of the $\mathrm{C} / \mathrm{N}$ ratio. A correlation between the peaks of polysaccharides and the drop in the removal yield of ammonium has already been observed $[9,10,11]$. The elimination of nitrates by the MBR is largely incomplete during the 160 days of operation.

There are several possible causes for a malfunction of the denitrification reaction: unmet anoxic conditions [44], not enough organic carbon [40], a wrong residence time between anoxic and aerobic zones, an inadequate temperature and/or $\mathrm{pH}$, an accumulation of nitrites or the presence of toxic compounds Seifert et Domka [53]. So, the poor denitrification performances could be the result of toxic compounds in HWW disrupting heterotrophic bacteria. Little evidence was provided in the literature about the influence of pharmaceuticals on the denitrification reaction. Kraigher et al. [35] show that the presence of drugs on very specific conditions can lead to a modification of the bacterial community and to a decrease of the performances of the denitrification reaction. A light denitrification inhibition was also observed by Prado et al. [48] in a MBR after the addition of the tetracycline antibiotic. Surfactants in HWW are known as possible inhibitors of the denitrification reaction in the grounds [53]. HWW, which are rich in drugs and surfactants because of the strict hygiene standards of healthcare services, seem to be responsible for the denitrification inhibition. The dilution of HWW by the synthetic substrate free of drugs and surfactants that allowed a partial denitrification highlights this observation.

The evolution of membrane fouling is analyzed by the monitoring pressures at the end of the membrane module, which allows the calculation of the transmembrane pressure (TMP) then the permeability. The evolution of the normalized permeability (at the initial value $\mathrm{Lp}_{20}{ }^{\circ} \mathrm{Cmax}$ listed $=58.6 \mathrm{~L} \mathrm{~h}^{-1} \mathrm{~m}^{-2} \mathrm{bar}^{-1}$ ) is divided into several distinct phases corresponding to the washing and to the feeding change of the MBR. The initial water permeability of the membrane $\mathrm{Lp}_{0}$, measured at $102 \mathrm{~L} \mathrm{~h}^{-1} \mathrm{~m}^{2} \mathrm{bar}^{-1}$, is consistent with the value given by the manufacturer. The membrane permeability decreases linearly until the 40th day during the phase 1 . Phase 2 from the 40th day to the 96th day, which corresponds to the change of sampling method and of feeding of the MBR by HWW alone, is characterized by a new linear drop in the loss of permeability similar to the one of phase 1 . The membrane had to be cleaned on the 97th day because of a more important TMP to reach a sufficient permeate flow. Phase 3 from the 97 th day to the 160th day, which corresponds to the MBR fed by HWW and the synthetic substrate, is characterized by a loss of linear permeability versus time less important than in phase 2 . The daily loss of membrane permeability was then reduced by $28 \%$ during the HWW dilution by a synthetic substrate.

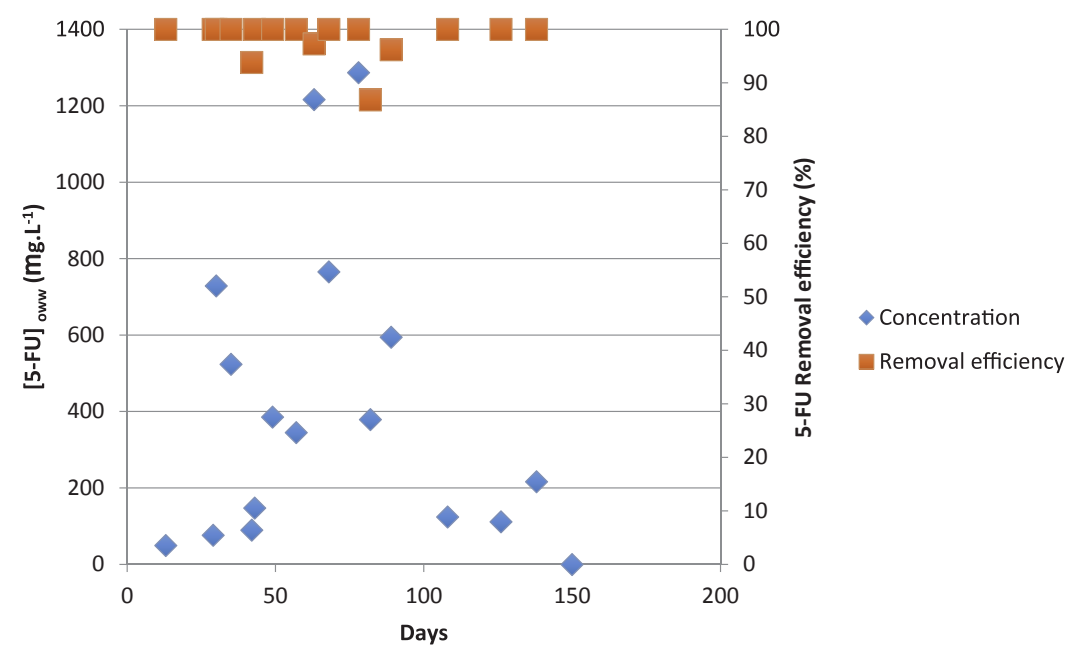

The reduction first indicates that the mixed liquor has become less fouled with the synthetic substrate intake than in phase 3 .

\subsection{Performances of eMBR on the removal of 5-FU}

Except on the 150th day, 5-FU has been systematically detected in HWW for the analyzed samples (Fig. 4). Concentrations vary from 0 to $1,287 \mu \mathrm{g} \mathrm{L}{ }^{-1}$. These concentrations are very important compared with those observed in previous studies between $35 \mathrm{ng} \mathrm{L}^{-1}$ and $122 \mu \mathrm{g} . \mathrm{L}^{-1}$ [41]. The analyzed permeate samples indicate a good removal of 5-FU by the eMBR since the reductions are more than 90\% (Fig. 4) whatever the initial concentration. Note that the concentration of 5-FU in the supernatant was always similar to the concentration in the permeate, ruling out the assumption of a retention of this pharmaceutical by the membrane in the biological tank or on the membrane.

Despite the very strong concentration more than $1 \mathrm{mg} \mathrm{L}^{-1}$ in HWW, the elimination of 5-FU remains above $95 \%$. The specific elimination rate constant seems relatively proportional to the initial concentration in 5-FU (pseudo first order). Therefore, 5-FU is almost entirely removed via biotransformation [41]. Degradation kinetics of 5-FU were achieved on sludge from the municipal WWTP from Rousset (France) and on sludge from hospital eMBR for 5 initial concentrations: 50-100-200-500-1000 $\mu$ g. $\mathrm{L}^{-1}$. Kinetics were carried out on $21 \mathrm{~h}$ in order to match the HRT of the eMBR. Sludge from the municipal WWTP is adjusted to the sludge concentration from the eMBR: $4.1 \mathrm{~g} \mathrm{~L}^{-1}$. Whatever the concentration, the reduction of 5-FU is always higher for acclimated sludge from the hospital than sludge collected in the municipal WWTP. In this concentration interval, activated sludge from the municipal WWTP also seems very efficient on the elimination of 5-FU since the minimum reduction is always above $80 \%$. It is however very important to note that despite the various drugs, metabolites and cleaning products in HWW, the biomass from hospital eMBR proved to be at least as successful as the sludge from the WWTP, which degraded 5-FU alone. Kinetic constants of $\mathrm{k}_{\mathrm{biol}}$ degradation were calculated between $\mathrm{t}=15 \mathrm{~min}$ and $\mathrm{t}=90 \mathrm{~min}$ since on this interval the term $\ln (\mathrm{C} /$ $\mathrm{C}_{0}$ ) is linear and indicates that the degradation kinetics is of pseudo-first order during the 90 first minutes (Fig. 5). The evolution of the constant of $\mathrm{k}_{\mathrm{biol}}$ degradation shows that acclimation step allows a faster degradation of 5-FU. An average increase by $34 \%$ is then reached for the eMBR sludge treating HWW compared with sludge in the WWTP. The evolution of $\mathrm{k}_{\mathrm{biol}}$ constants shows that a threshold was reached for sludge in the WWTP whereas it may still evolve after $1000 \mu \mathrm{g} \mathrm{L}^{-1}$ for sludge in the eMBR treating HWW. So, the minimum inhibition concentration may be lower for sludge in the WWTP than for sludge in the hospital eMBR. The removal of 5-FU is attributed to either biotransformation or sorption [25].

Fig. 4. 5-FU concentrations detected and removal efficiency in oncological ward wastewater and 5-FU removal efficiency during the 1st experimental campaign (eMBR). 


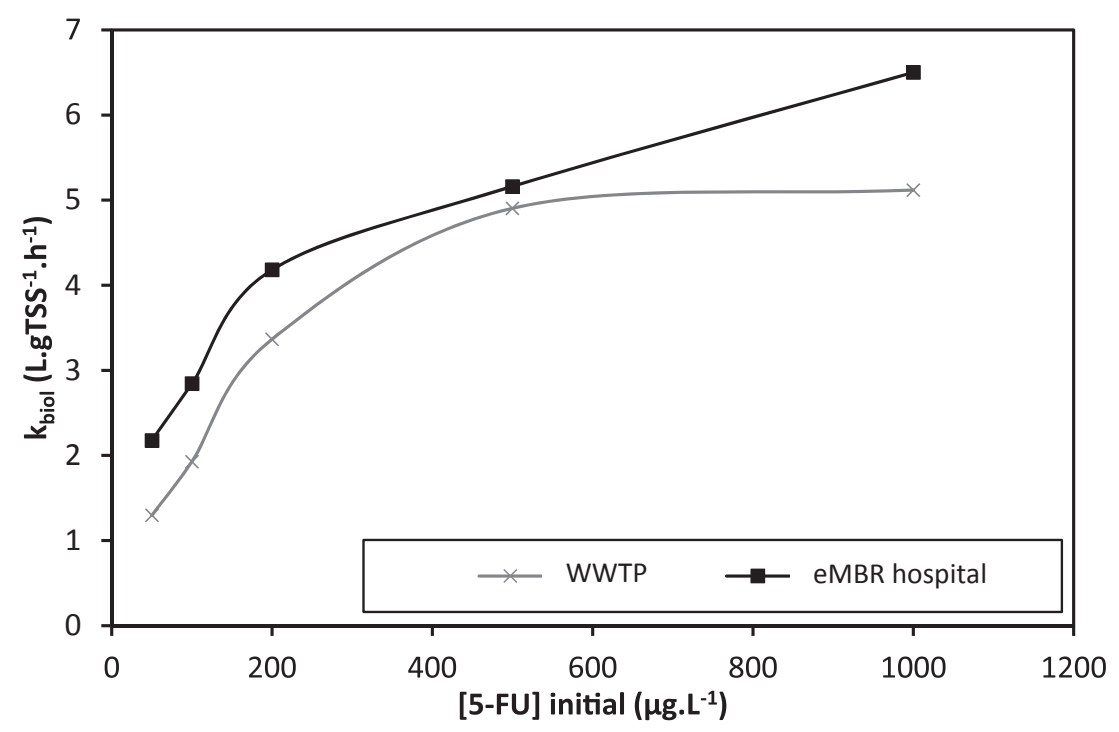

Fig. 5. Evolution of the degradation constant $\mathrm{k}_{\mathrm{biol}}$ for both activated sludges from eMBR hospital and municipal WWTP.

\section{Results with a sMBRe}

This second experimental campaign to acclimate activated sludge to HWW was conducted with the configuration of external submerged membrane bioreactor (sMBRe). In this configuration, the used membranes are hollow fibers with a $100 \mathrm{kDa}$ cutoff. It is noteworthy that the membrane surface has doubled from 0.2 to $0.4 \mathrm{~m}^{2}$ from the 56th day. New indicators of the biomass acclimation to HWW were tested during the second campaign such as antibiotic resistance and respirometry tests. Purification efficiency on the drug pollution is assessed on 4 drugs among which 2 out of the 3 most consumed anticancer drugs in the oncology ward (ifosfamide and cyclophosphamide), one antibiotic (sulfamethoxazole) and one painkiller (codeine).

\subsection{Acclimation}

HWW were continuously collected during the night. The evolution of carbon (COD) (from 148 to $1135 \mathrm{mg} \mathrm{L}^{-1}$ ) and nitrogen $\left({\mathrm{N}-\mathrm{NH}_{4}}^{+}\right.$) (from 7 to $69 \mathrm{mg} \mathrm{L}^{-1}$ ) pollution show a lot of fluctuations of COD and ammonium concentrations during the 180 acclimation days (Fig. 6).
This concentration discrepancy logically implies an uneven trend of the $\mathrm{C} / \mathrm{N}\left(\mathrm{COD} / \mathrm{N}-\mathrm{NH}_{4}{ }^{+}\right)$ratio of HWW. The main sampled HWW have a C/ $\mathrm{N}$ ratio comprised between 5 and 30 . The average $\mathrm{C} / \mathrm{N}$ ratio of 17.9 is thus lower than during the first campaign (32.3) indicating a nitrogen amount more important versus carbon but closer to the ideal desired ratio of 20 .

\subsection{Overall performances of the sMBRe}

The loading of the sMBRe hospital was carried out with activated sludge from the municipal WWTP from Rousset (France). The initial TSS concentration is $6.8 \mathrm{~g} \mathrm{~L}^{-1}$. The TSS and F/M evolutions were divided into 4 distinctive phases (Fig. 7a). Purification efficiency on COD, ammonium and nitrates were also presented as the 4 phases were described (Fig. $7 \mathrm{~b}-\mathrm{c}$ ). The second experimental campaign was marked again by an almost continuous intense foaming of the mixed liquor in the aerated tank reflecting the bacterial stress exerted by pharmaceuticals and/or the significant presence of surfactants contained in HWW.

During the first experimental campaign, one of the assumptions to explain the low biomass growth over the long term was about some of

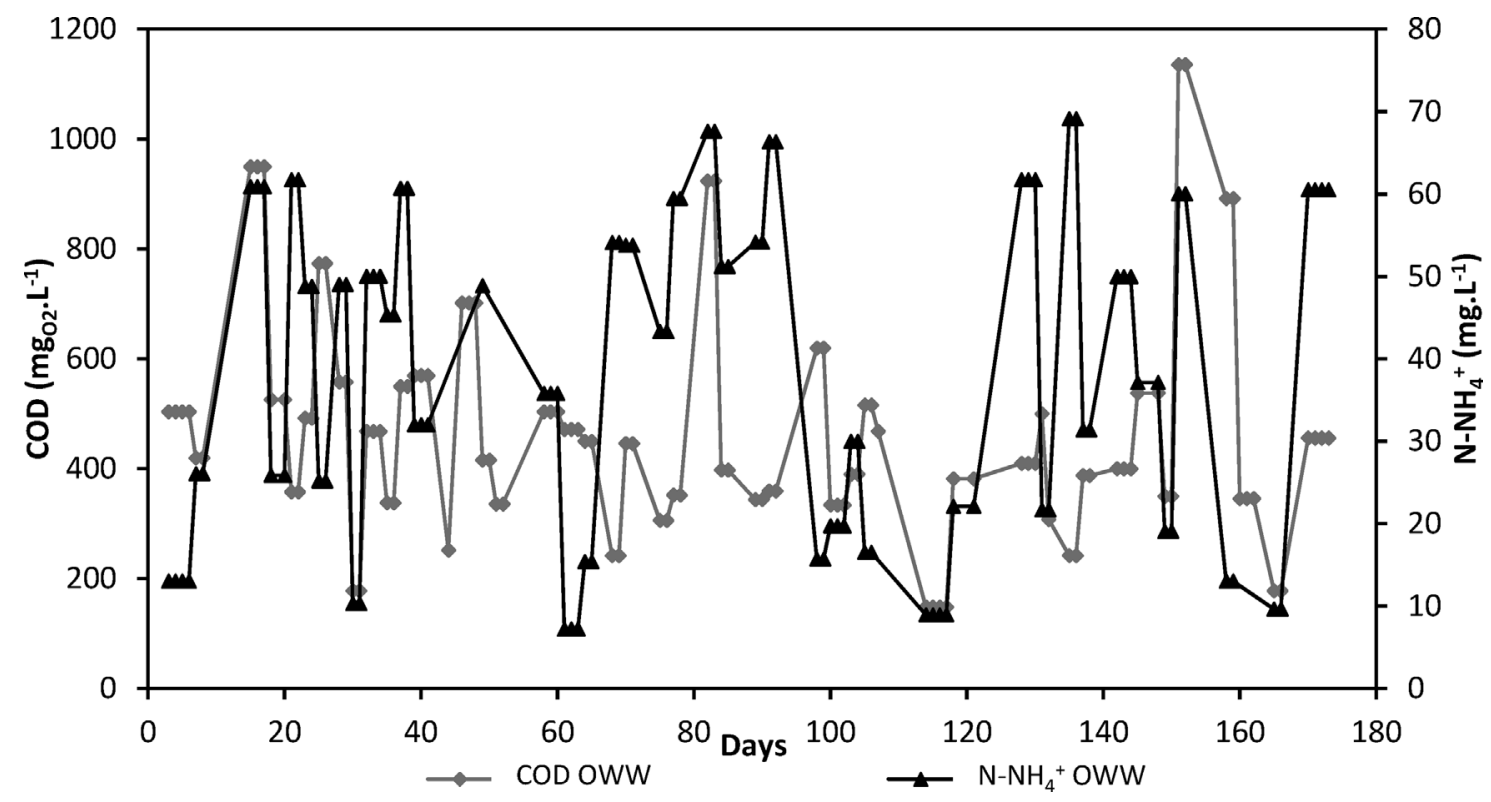

Fig. 6. Evolution of COD and ammonia in OWW during the 2nd experimental campaign (sMBRe). 

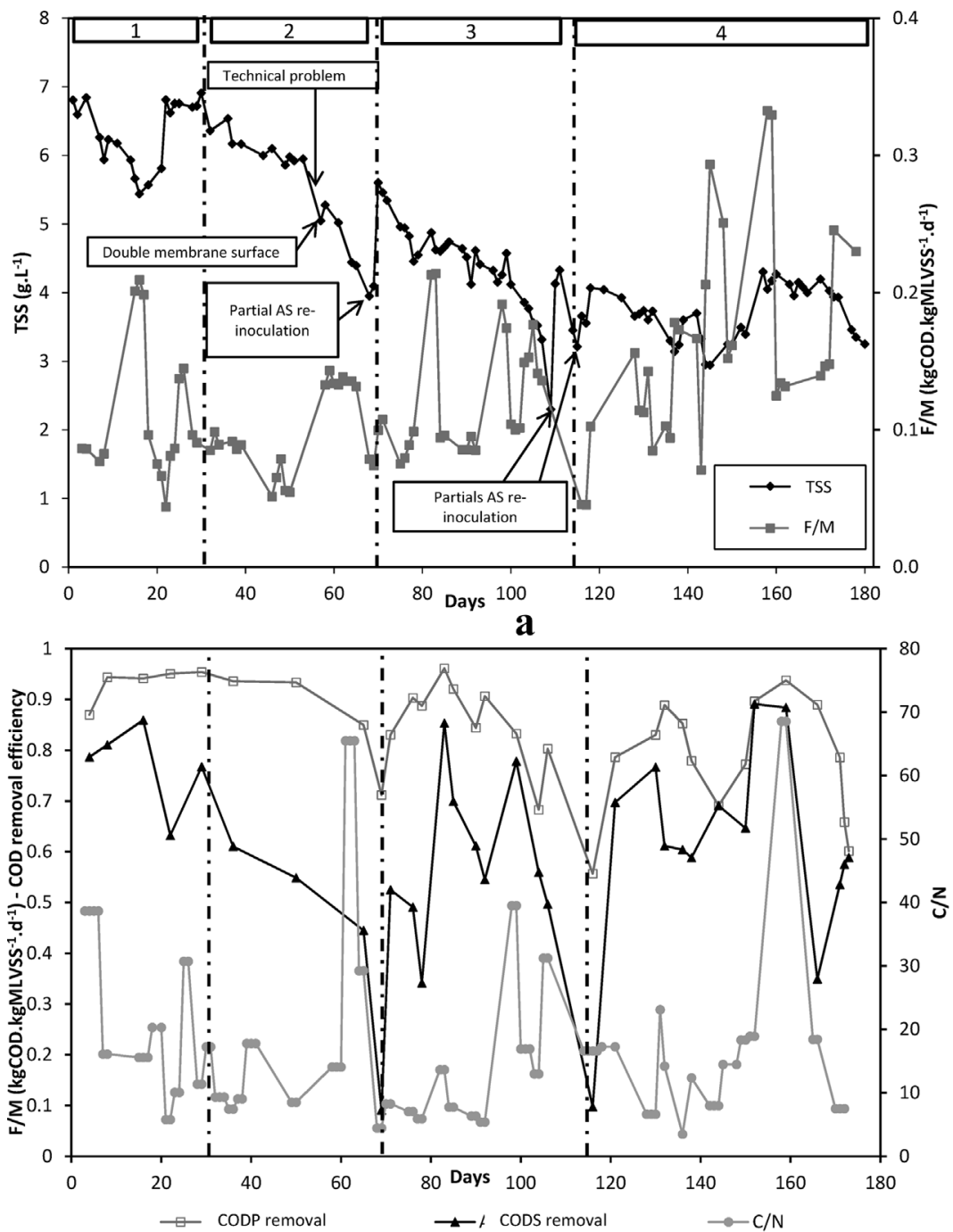

b

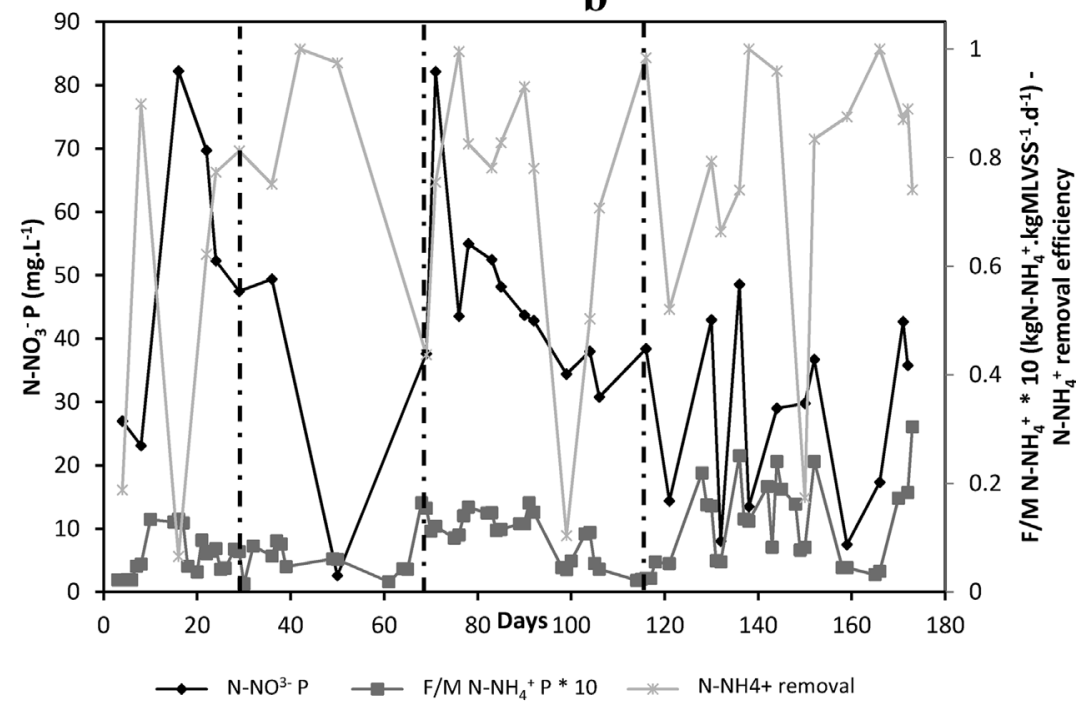

Fig. 7. Evolution of (a) TSS and the F/M COD ratio (sMBRe) (b) of COD removal efficiencies in supernatant and permeate and $\mathrm{C} / \mathrm{N}$ ratio (sMBRe) (c) of nitrates concentration in permeate, the ammonia $\mathrm{F} / \mathrm{M}$ ratio and the removal efficiency of ammonia during the 2nd experimental campaign $(\mathrm{sMBRe}=$.

C

the specific compounds of HWW that would exert an inhibition on the reproductive abilities of microorganisms. It was thus decided to apply conditions of limiting substrate to the biomass to get microorganisms used to the presence of specific substances contained in HWW and to force their degradation. This strategy of limiting substrate explains the low average $\mathrm{F} / \mathrm{M}$ value in COD to $0.09 \mathrm{~kg}_{\mathrm{COD}} \mathrm{kg}_{\mathrm{vss}}{ }^{-1} \mathrm{~d}^{-1}$ during the first 50 days. The average COD concentration in HWW lower by $28 \%$ on COD during the $2^{\mathrm{d}}$ campaign compared with the first one led to apply 
occasional F/M sometimes very low. Further to the problems faced on the biomass performances, acclimation was then conducted with a double membrane area $\left(0.2-0.4 \mathrm{~m}^{2}\right)$ from the 56th day to apply a higher F/M. According to the first experimental campaign, the VSS rate in TSS remained relatively constant during acclimation to $88 \pm 3 \%$.

\subsubsection{Phase 1: 0-30th day}

Unlike the 1st experimental campaign, the biomass concentration remained relatively steady during the first days. The hydrodynamic conditions of the sMBRe configuration are indeed softer than the external configuration (eMBR) since it is not necessary to impose a high flow velocity within the membrane, as fouling is controlled by the injection of air bubbles in the membrane module. Contradictory evolutions are noted for biomass and the removal of $\mathrm{COD}_{\mathrm{S}}$ during this first phase: (i) The minor loss of TSS observed until the 16th day to $5.4 \mathrm{~g} \mathrm{~L}^{-1}$ indeed coincides with a proper removal of $\mathrm{COD}_{\mathrm{S}}$ while (ii) the phase of growth, which returns to the initial concentration of $6.8 \mathrm{~g} \mathrm{~L}^{-1}$ in the 22nd day, is bound with the rough decrease of the reduction of $\mathrm{COD}_{S}$ between the 16th and the 22nd day. The drop seems to be the result of a very low $\mathrm{F} / \mathrm{M}$ to $0.04 \mathrm{~kg}_{\mathrm{COD}} \mathrm{kg}_{\mathrm{vss}}{ }^{-1} \mathrm{~d}^{-1}$ because of HWW rather less loaded that on the 16th day. The removal of ammonium also fluctuates slightly. Autotrophic bacteria could be occasionally sensitive to a present compound or a lack of inorganic carbon in HWW since the removal of ammonium has reached again the correct values from the 22nd day. Meanwhile, a pronounced inhibition of denitrification occurs early in this second experimental campaign despite a limited potential constitution of nitrates due to the weak removal of ammonium.

\subsubsection{Phase 2: 30-69th day}

After TSS stabilized until the 30th day, the phase is at first marked by a very slow loss of biomass until the 53 rd day to $5.9 \mathrm{~g} \mathrm{~L}^{-1}$ then by a decrease to $3.9 \mathrm{~g} \mathrm{~L}^{-1}$ on the 68 th day because of a technical problem. On the 69th day an overall drop in the sMBRe performances has been noticed with $\mathrm{COD}_{\mathrm{S}}$ and ammonium removals to $9 \%$ and $44 \%$ respectively. This drop can be the result of the technical problem but also of the very important variation of the $\mathrm{C} / \mathrm{N}$ ratio, from 65 to 4.5 from the 61th to the 68th day [21] but autotrophic bacteria seem to have better withstood these conditions than heterotrophic bacteria, namely that the $\mathrm{C} / \mathrm{N}$ ratio only is not enough to explain this overall drop in the sMBRe performances. Denitrification seems very effective as evidenced by removal of $97 \%$ of ammonium on the 50th day indicating a high potential for the constitution of nitrates. The little $\mathrm{COD}_{\mathrm{S}}$ removal during this period also highlights a significant retention by the membrane of the non-degraded COD to obtain an apparent high removal despite altered biological performances. A partial reloading was performed on the 69th day with activated sludge of the STEP from Rousset to compensate for the generated losses, for the TSS concentration of the sMBRe going back then up to $5.6 \mathrm{~g} \mathrm{~L}^{-1}$. The sMBRe hospital is thus made up with $30 \%$ of non-acclimated activated sludge from the municipal WWTP on the 69th day.

\subsubsection{Phase 3: 70-115th day}

A new continuous biomass loss has been observed during phase 3 . This more pronounced loss resulting from reloading since the TSS concentration fell from 5.6 to $4.4 \mathrm{~g} \mathrm{~L}^{-1}$ from the 70th to the 78th day then decreased albeit moderately, similarly to phase 2 until the 100th day to reach $4.1 \mathrm{~g} \mathrm{~L}^{-1}$. It is associated with an uneven $\mathrm{COD}_{\mathrm{S}}$ and a very good ammonium removal probably related to the relative stabilization of the $\mathrm{C} / \mathrm{N}$ ratio. However, the implementation of a double membrane surface involves a decrease of the $\mathrm{COD}_{\mathrm{P}}$ reduction. The higher membrane area available slows down the fouling impact on the retention of the non-biodegraded residual COD. A second partial reloading in two steps, on the 109th and 115th days was necessary to compensate for biomass losses, TSS concentrations then came back up to $4.1 \mathrm{~g} \mathrm{~L}^{-1}$ and was then made up with $44 \%$ non-acclimated activated sludge on the 115th day.

\subsubsection{Phase 4: $115-180$ th day}

A slow biomass loss similar to the one in phases 2 and 3 has started again. Partial reloading has likely affected the $\mathrm{COD}_{\mathrm{S}}$ removal immediately with a rough drop to $10 \%$ on the 116 th day, but not ammonium removal with $98 \%$. On the contrary, ammonium removal fell to $52 \%$ on the 121 st day whereas $\mathrm{COD}_{\mathrm{S}}$ removal came up to reach values above $70 \%$. The results indicate again that autotrophic and heterotrophic bacteria are affected in a different way by HWW. From the 144th to the 157th day, a significant biomass increase from 2.9 to $4.3 \mathrm{~g} \mathrm{~L}^{-1}$ was obtained and linked to a relatively steady and ideal C/N ratio (it is included between 15 and 20) and with a strong F/M. The permeate flow was increased noticeably since the 136th day in an attempt to get bacterial growth again (from $1 \mathrm{~L} \mathrm{~h}^{-1}$ since the beginning of phase 4 to an average of $1.35 \mathrm{~L} \mathrm{~h}^{-1}$ between the 136th and 157th days). This phase of growth has also been marked by the absence of foam in the reactor for the first time since the start of biomass acclimation, indicating a significant decrease in the medium toxicity and/or the absence of surfactants in HWW. Good purification efficiency was related to the bacterial growth.

HWW have a very strong inhibitory effect on the reproductive capacities of biomass that does not seem to respond well to changes in composition of the effluent. Conflicting performances were observed in similar operating conditions throughout the acclimation and would mean that the specific composition of HWW is responsible for the antinomy by the observed performances of biomass of the sMBRe hospital. It is thus possible that HWW do not affect both types of bacteria with the same kinetics by HWW nor over the same duration. The $\mathrm{COD}_{\mathrm{S}}$ removal has experienced a lot of fluctuations, which seem to be linked to the variations of $\mathrm{C} / \mathrm{N}$ ratio. The 4 carbon peaks on the 61st, 98th, 105th and 158th days have all caused a dramatic drop in the $\mathrm{COD}_{\mathrm{S}}$ reduction. On the contrary, the carbon peaks did not systematically alter the performances of autotrophic bacteria. So, a selective inhibition of heterotrophic bacteria was noticed occasionally with an operational denitrification and a very weak COD removal. The non-repeatability of the results indicates that the follow-up of conventional indicators of HWW pollution does not allow the full use of the MBR pilot since the inhibition of activated sludge sometimes seems related to specific pollutants and not to the proportion of carbon and nitrogen in HWW. The fouling of $100 \mathrm{kDa}$ hollow fibers has a major influence on the retention of $\mathrm{COD}_{\mathrm{S}}$ and achieves excellent overall COD removal by sMBRe despite significant fluctuations in purification performance of biomass. Similarly to the first experimental campaign, the denitrification reaction proved again very inhibited throughout acclimation while the physical and chemical parameters (temperature, dissolved oxygen, $\mathrm{pH}$ ) were optimum to provide an operational denitrification. Two experiments in batch reactor were performed at the end of the 2nd experimental campaign to check whether inhibition of the denitrification reaction could come from the lack of easily assimilated carbon: (i) an anoxic batch reactor in endogenous condition (no outer substrate intake); (ii) an anoxic batch reactor in exogenous condition (with organic carbon intake easily biodegradable (sugar)).

The dissolved oxygen concentration was controlled and remained null during the experiment. No denitrification was observed in both batch reactors after $4 \mathrm{~h}$ experiment, nitrate concentrations remained constant. So, inhibition of the denitrification reaction does not come from the absence of organic carbon easily digestible. The observations of the first experimental campaign would therefore be confirmed: denitrification inhibition would be caused by products disturbing the transfers of material within the bacterial flocs in the anoxia tank. These products, such as surfactants, in large quantities in HWW because of the hospital activity could also be partly responsible for the foaming of the mixed liquor observed in almost all of the second experimental campaign. These products would disrupt less heterotrophic bacteria in the aerobic tank because of their partial degradation due to presence of dissolved oxygen in this tank. 


\subsection{Membrane fouling}

It should be noted that the membrane surface was doubled from $0.2 \mathrm{~m}^{2}$ à $0.4 \mathrm{~m}^{2}$ from the 56th day in order to apply higher F/M. The representation of the membrane fouling evolution was achieved from the fouling resistance $\left(\mathrm{R}_{\text {fouling }}\right)$ obtained from a resistance model (Fig. 8). TMP and flux varied during the 180 days of the campaign depending on membrane fouling, membrane ageing, TSS concentrations, etc. The TMP varied from 0.06 to 0.75 bar and the flux from 2 to $5 \mathrm{~L} \mathrm{~h}^{-1} \mathrm{~m}^{-2}$. The membrane fouling was calculated from these values. From the 12th day of acclimation a relaxation (one minute) and a backwash (1 min-0.5 bar) of the hollow fibers were performed manually twice a day in order to slow down the fouling constitution. Several incidents (fiber break, technical problem) occurred during the 180 days of the sMBRe operation. The fouling evolution is roughly similar for the two first phases with the $0.2 \mathrm{~m}^{2}$ surface membrane module. With the double surface membrane module, the loss of permeability is initially more important because of a higher permeate flow and because of the significant TSS loss at that period that could lead to a release of soluble microbial products conducive to fouling. The fouling formation kinetics can then be compared with the one of the 55 first days and corresponds to a relative stabilization of TSS and to a similar permeate flow. The forthcoming phase, from the 96 th to the 125th day is characterized by a faster fouling formation and coincides with important fluctuations of the TSS concentration and with reloading of activated sludge. The cell lysis could therefore lead again to the release of compounds with a strong fouling capacity. Kinetics of the fouling formation is then attenuated in the biomass stagnation and growth and indicates the good physiological state of activated sludge. The role of the biomass state is thus significant in the membrane fouling formation since the phase is associated with an important increase in the permeate flow. The fouling degree has a major influence on the $\mathrm{COD}_{\mathrm{S}}$ retention not removed by bacteria (Fig. 8). The retention rate (RR) of $\mathrm{COD}_{\mathrm{S}}$ becomes rapidly important and remains high until the 93rd day and the change of membrane module because of a broken hollow fiber. This high retention is associated with a rapid drop of the membrane permeability, despite a fiber backwash and relaxation, and of the chemical cleaning of the 21st day too. For a similar permeate flow, when the membrane surface is doubled, the $\mathrm{COD}_{\mathrm{S}}$ retention rate is weaker and fluctuates. From the 93rd day, the operation with higher membrane permeabilities directly influences the $\mathrm{COD}_{\mathrm{S}}$ retention rate, which oscillates between 30 and $63 \%$ until the 139th day. The implementation of a new membrane on the 145th day confirms the major influence of fouling on the $\mathrm{COD}_{\mathrm{S}}$ retention since it becomes null. Although operating with a significant fouling degree improves the apparent $\mathrm{COD}_{\mathrm{S}}$ removal, the important retention of specific substances in the reactor could be an assumption to explain the occasional alterations of the biomass purification efficiency (Fig. 9).

It is noteworthy that long-term TSS drops are obtained from the 23rd to the 105th day whereas the average COD retention rate of the surfactant is $67 \%$. Then, the average $\mathrm{COD}_{\mathrm{S}}$ retention factor is only $38 \%$ and coincides with the biomass stabilization and growth phases. The last low values of the $\mathrm{COD}_{\mathrm{S}}$ retention factor correspond to the last change of membrane module. An important $\mathrm{COD}_{\mathrm{S}}$ retention by the membrane and its fouling could lead to the accumulation of the toxic compounds in the biological reactor, which would disrupt the biomass growth. These observations thus provide another assumption regarding the parameters that could influence the biomass growth.

\subsection{Antibiotic resistance and purification efficiency}

Antibiograms were performed to quantify the evolution of antibiotic resistant properties of the biomass during the second experimental campaign. The acquisition of the antibiotic resistance is reported to occur at sub-inhibitory concentrations, which favor the development of antibiotic-resistant bacteria [24]. The 6 most consumed antibiotics in the oncology unit to which the sMBRe hospital is connected have been selected for this follow-up. There are penicillin types amoxicillin and ticarcillin, cephalosporin antibiotics of third generation ceftazidime and ceftriaxone, fluoroquinolone antibiotics ciprofloxacin and carbapenem meropenem. The minimum inhibitory concentration (MIC) of antibiotics on activated sludge is calculated from measured inhibitory diameters. The biomass MIC of the sMBRe are compared with those of the municipal WWTP from Rousset $\left(\mathrm{MIC}_{0}\right.$ ) to quantify the acquired

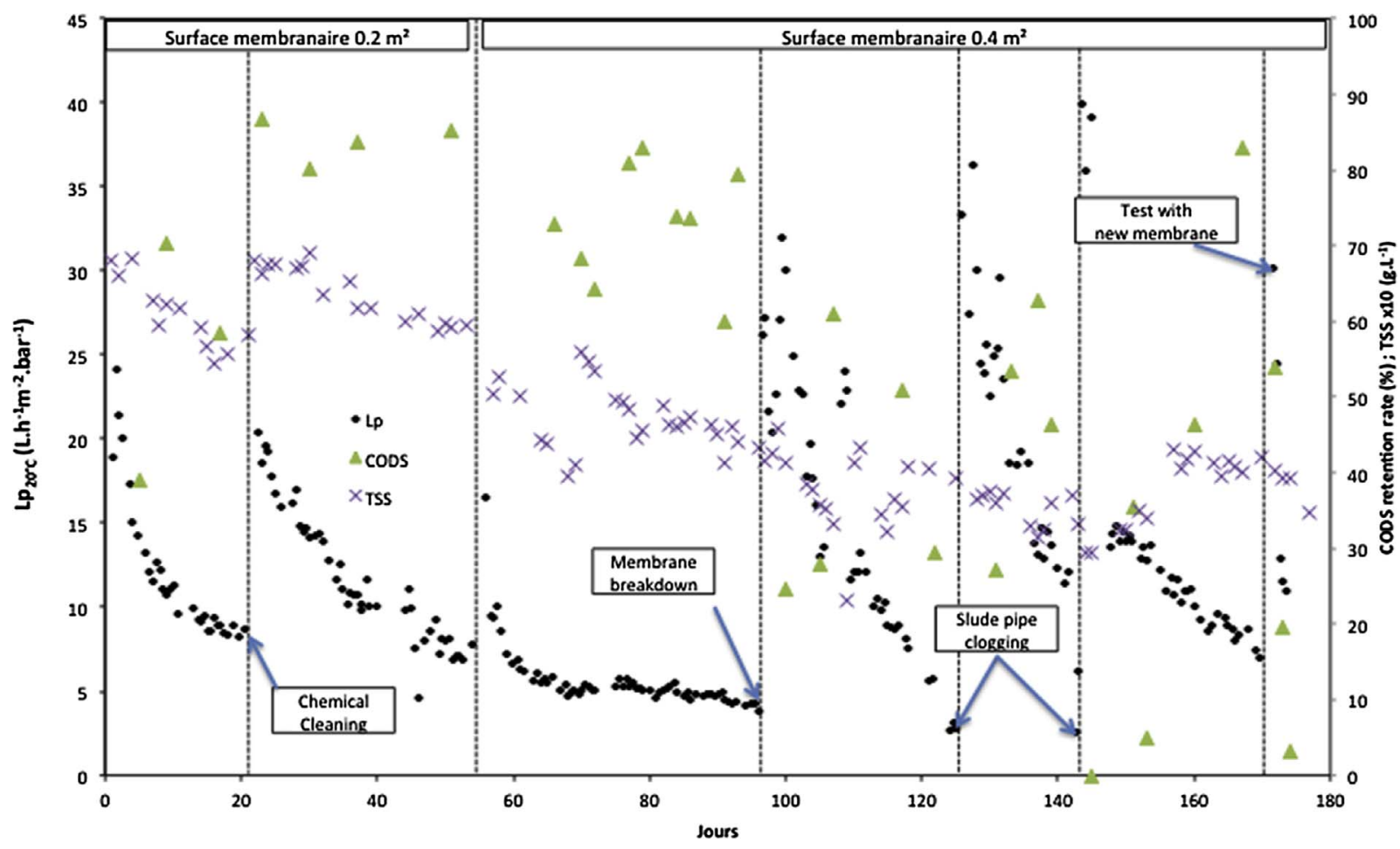

Fig. 8. Evolution of the membrane permeability, the supernatant COD retention rate and TSS $(\times 10)$ during the 2nd experimental campaign (sMBRe). 


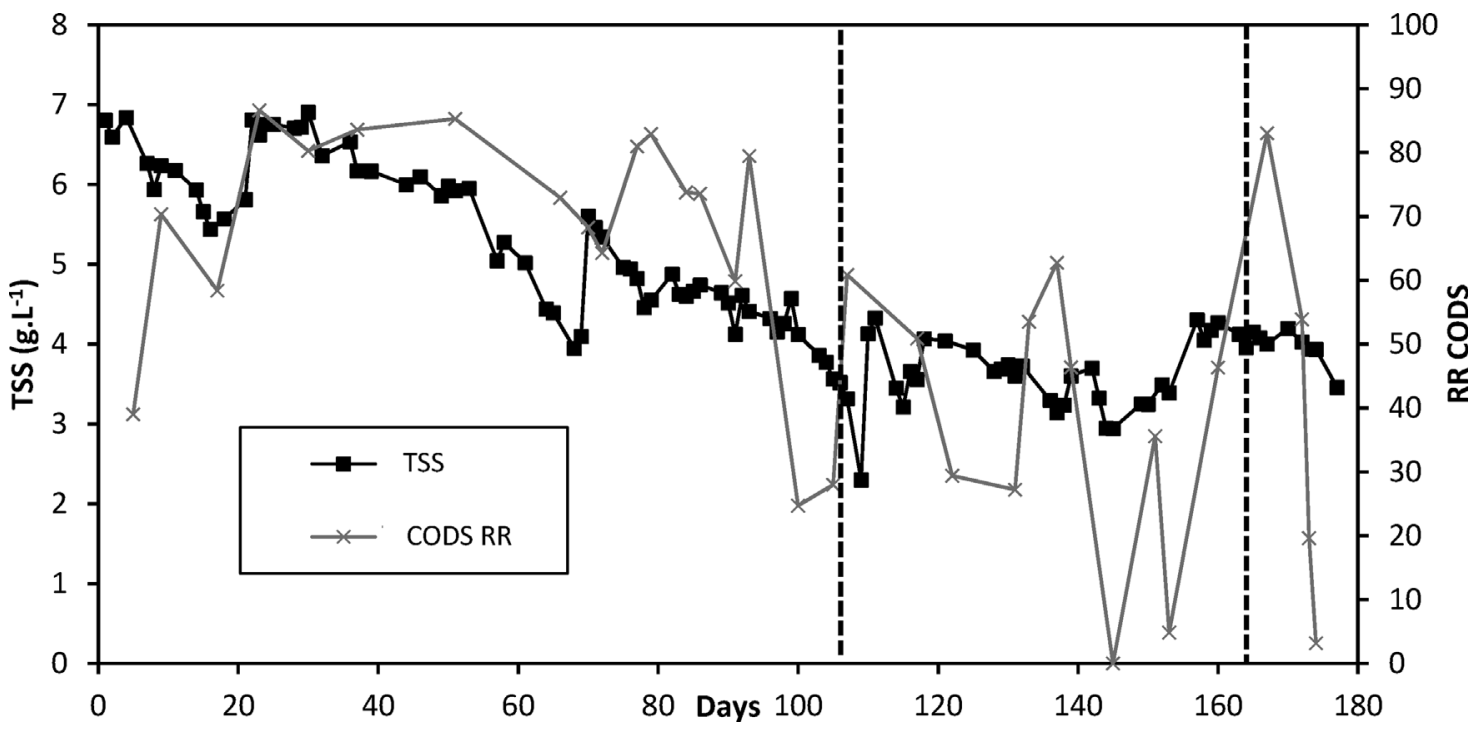

Fig. 9. Influence of the COD supernatant retention rate on the evolution of the biomass concentration (sMBRe).

antibiotic resistance (Fig. 10). So, the higher the ratio MIC/MIC $\mathrm{C}_{0}$ is, the more the biomass develops an antibiotic resistance. The overall antibiotic resistance of activated sludge has logically increased during acclimation. Biomass has rapidly become completely resistant to both types of penicillin. This result is not surprising since initial activated sludge of the municipal WWTP already showed an important resistance to both antibiotics with a $\mathrm{MIC}_{0}$ far higher than for other molecules (Table 3). The amoxicillin measured antibiotic resistance agrees with its removal in the conventional WWTP with activated sludge since $100 \%$ removals were observed [63,70] and 99\% [64].

The maximum antibiotic resistance degree has been reached for most antibiotics on the 99th day when ciprofloxacin and ceftriaxone can no longer be quantified. At that time, the COD reduction in the supernatant has come back up to $78 \%$ but ammonium dropped to $10 \%$ after the carbon peak in HWW. The carbon peak on the 98th day combined with an increase in $\mathrm{F} / \mathrm{M}$ induces the simultaneous decrease of the antibiotic resistance of meropenem, ticarcillin and ciprofloxacin between the 99th day and the 105th day. So concurrently to the TSS evolution and to the $\mathrm{COD}_{\mathrm{S}}$ removal, the biomass antibiotic resistant properties could also be short-term impacted by the significant composition fluctuations of HWW. On the contrary, the biomass was completely ceftazidime resistant on the 105th day. The decrease of

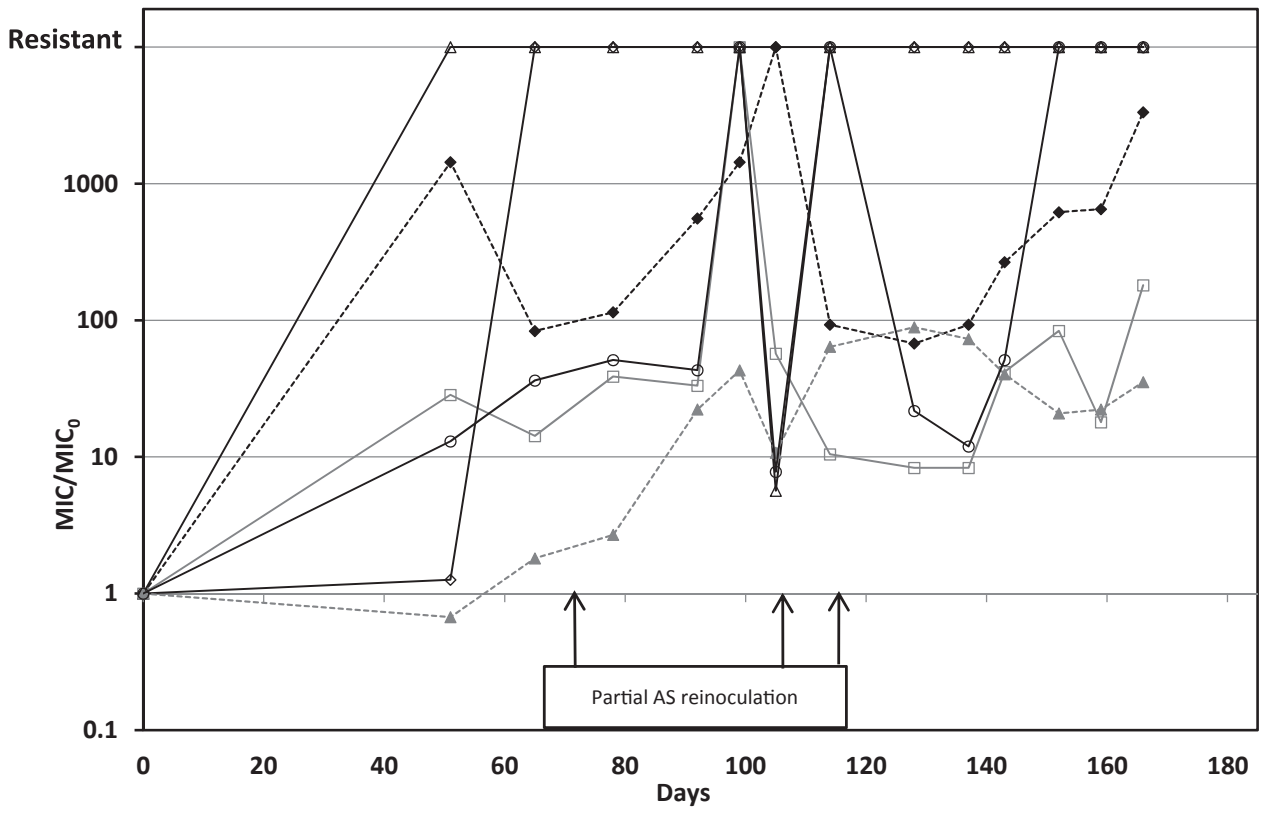

Fig. 10. Evolution of the biomass resistance to the most used antibiotics in the oncological ward (sMBRe).

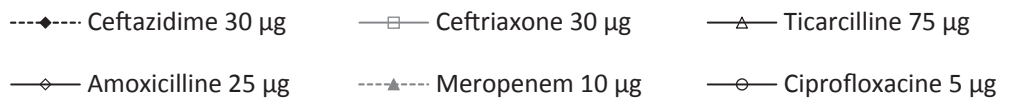

Values of $\mathrm{MIC}_{0}$ (mg. L ${ }^{-1}$ )

Amoxicillin 34.6 - Ceftazidime 0.2 - Ceftriaxone 0.7

Ciprofloxacin 2.7 - Meropenem 0.1 - Ticarcillin 90.6 
Table 3

Membrane retention rate for the supernatant samples analysed (sMBRe).

\begin{tabular}{|c|c|c|c|c|c|c|c|c|c|c|}
\hline Date & Molecule & $\begin{array}{l}\mathrm{OWW}_{\text {total }} \\
\left(\mu \mathrm{g} \mathrm{L}^{-1}\right)\end{array}$ & $\begin{array}{l}\text { Supernatant } \\
\left(\mu \mathrm{g} \mathrm{L}^{-1}\right)\end{array}$ & $\begin{array}{c}\text { Biological reactor } \\
\text { removal } \\
\text { efficiency }(\%)\end{array}$ & $\begin{array}{l}\text { Permeate } \\
\left(\mu \mathrm{g} \mathrm{L}^{-1}\right)\end{array}$ & $\begin{array}{l}\text { MBR total } \\
\text { removal } \\
\text { efficiency }(\%)\end{array}$ & $\begin{array}{c}\text { Retention rate } \\
\text { pharmaceutical (\%) }\end{array}$ & $\begin{array}{l}R_{\text {fouling }} \\
\left(\mathrm{m}^{-1}\right)\end{array}$ & $\begin{array}{c}\text { COD } \\
\text { retention rate } \\
(\%)\end{array}$ & $\begin{array}{l}\mathrm{COD}_{\mathrm{S}} \\
\left(\mathrm{mg} \mathrm{L}^{-1}\right)\end{array}$ \\
\hline \multirow[t]{4}{*}{ 115th day } & CD & 375 & 80 & 78.7 & 15 & 96.0 & 81.3 & $3.9 .10^{13}$ & 50.9 & 133.6 \\
\hline & $\mathrm{CP}$ & 687 & 552 & 19.7 & 76 & 88.9 & 86.2 & & & \\
\hline & $\mathrm{IF}$ & 1030 & 809 & 21.5 & 73 & 92.9 & 91.0 & & & \\
\hline & SM & 1190 & 57 & 95.2 & 3 & 99.7 & 94.7 & & & \\
\hline \multirow[t]{4}{*}{ 128th day } & $\mathrm{CD}$ & $<\mathrm{LQ}$ & $<\mathrm{LQ}$ & - & $<\mathrm{LQ}$ & - & - & $1.3 .10^{13}$ & 27.2 & 95.6 \\
\hline & $\mathrm{CP}$ & 450 & 278 & 38.2 & 205 & 54.4 & 26.3 & & & \\
\hline & $\mathrm{IF}$ & 900 & 614 & 31.8 & 578 & 35.8 & 5.9 & & & \\
\hline & SM & 2000 & 2170 & -8.5 & 1460 & 27.0 & 32.7 & & & \\
\hline \multirow[t]{4}{*}{ 143rd day } & CD & 375 & 108 & 71.2 & 87 & 76.8 & 19.4 & $6.1 .10^{12}$ & 0 & 123.6 \\
\hline & $\mathrm{CP}$ & 609 & 386 & 36.6 & 307 & 49.6 & 20.5 & & & \\
\hline & IF & 1620 & 1010 & 37.7 & 800 & 50.6 & 20.8 & & & \\
\hline & SM & 2500 & 1530 & 38.8 & 482 & 80.7 & 68.5 & & & \\
\hline
\end{tabular}

ceftazidime resistance on the 114th day could be due to a latency required for this antibiotic or to partial reloading with activated sludge less resistant than sludge developed in the hospital sMBRe, which would specifically altered this antibiotic resistance. Antibiotic resistances of ciprofloxacine, ceftriaxone and ceftazidime keep on evolving until the end of acclimation whereas the meropenem resistance seems to reach a stage. Meropenem is besides the only tested antibiotic, which has always had an inhibitory effect that can be quantified on microorganisms [1]. Biomass has however gained a significant resistance to this antibiotic over time because it is 35 times stronger than the municipal WWTP sludge. Another degradation test showed the nonbiodegradability of ceftriaxone [30], which can explain its very low $\mathrm{MIC}_{0}$. Ciprofloxacin is partly removed in the municipal conventional WWTP, its reduction lies between 18 and 89.8\% [42]. So, ciprofloxacin resistance is acquired more slowly than for penicillins but is higher (resistance cannot be measured at the end of acclimation) than for ceftriaxone.

The resistance acquisition via biomass seems to agree with the antibiotic classification. Biomass has indeed become easily resistant to both penicillin types and the $\mathrm{MIC}_{0}$ and $\mathrm{MIC}_{163 \mathrm{j}}$ for both cephalosporin types are of the same order of magnitude. Antibiotic resistance seems to be true for antibiotics with the same mode of action [39]. A specific antibiotic does not need to be in HWW for the bacterial community of activated sludge to become resistant since it can develop a crossed resistance via another antibiotic in feed. The strong acquired resistance to both penicillin types is not surprising because apart from their high
$\mathrm{MIC}_{0}$, both antibiotics are by far the most frequently consumed in oncology ward. A crossed resistance to cephalosporin of 3rd generation can also be carried out via cefixime, however consumed in small quantities in the ward. Finally, carbapenems are known to be antibiotics stronger than penicillins and are therefore used as a last resort when other antibiotics did not work. Meropenem is the only carbapenem used in the oncology ward, its usage specific to critical cases combined with a systematic efficiency justifies the lowest resistance degree reached compared with another tested antibiotic. However, the resistance at the end of acclimation is identical to the amoxicillin initial one. The meropenem resistance stagnation may be due to its absence in HWW during a prolonged period.

After 180 operating days, biomass has developed a very strong resistance to the tested antibiotics, from 35 times more to completely resistant. The results demonstrate the adaptation abilities of microorganisms to molecules initially designed to destroy them. Despite the difficulties to obtain a significant biomass growth during the second experimental campaign, it is noteworthy that antibiotic resistance is still evolving for some antibiotics. A stage seems to be reached regarding meropenem, which is the antibiotic with the most significant inhibitory effect on biomass throughout acclimation to HWW. These results confirm Stadler's results [56] that highlighted the influence of HWW on the bacterial diversity and the dissemination of resistant genes within the bacterial community. So, very concentrated antibiotics in HWW compared with UWW favor the development at a high degree of antibiotic resistance within the purification biomass.

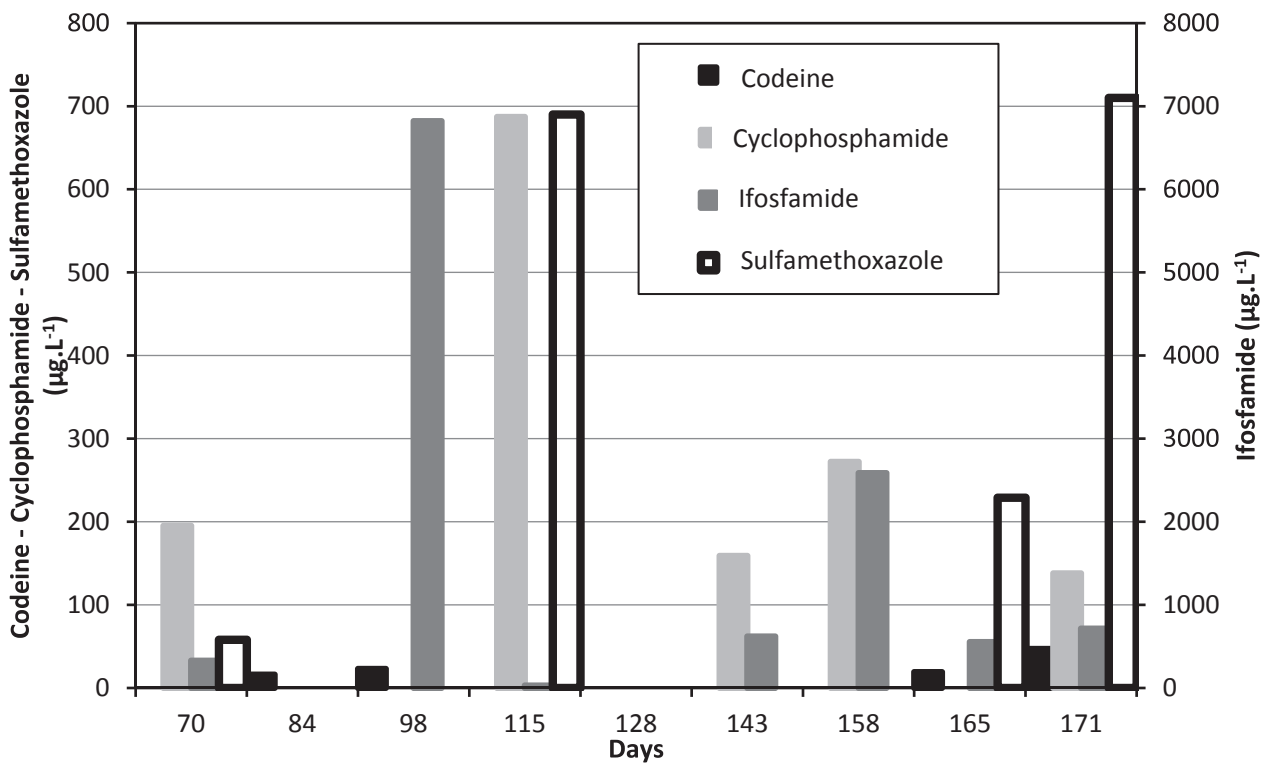

Fig. 11. Concentrations of the selected pharmaceuticals in OWW (before doping) (sMBRe). 


\subsection{Detection of the selected drugs and removal via sMBRe}

The MBR performances are quantified from anticancer ifosfamide (IF) and cyclosphosphamide (CP), sulfamethoxazole (SM) antibiotic and codeine (CD) painkiller. As well as 5-FU, IF, CP and SM are highly concentrated in the sampled HWW (Fig. 11). Very important concentrations were collected for ifosfamide: $6.8 \mathrm{mg} \mathrm{L}^{-1}$ on the 98th day and $2.6 \mathrm{mg} \mathrm{L}^{-1}$ on the 158th day. Detection frequencies and concentrations obtained show the strong variability of the pharmaceuticals composition of the collected HWW. Indeed, as the MBR is only connected to 6 rooms, the composition of the collected effluents depends on a number of patients (maximum 9) with different pathologies. The very strong drug identified concentrations can once again be allocated (i) to the discontinuous sampling during the night to avoid dilution of HWW by shower waters and (ii) originally HWW only from patient rooms. IF, CP and SM concentrations in HWW are logically higher than the ones in overall HWW of the previous studies (Table 1). To ensure the presence of the selected drugs in the feeding source of the MBR pilot and to quantify the sMBRe performances on their removal, HWW collected in the storage tank were exceptionally doped on the sampling days with random but known concentrations. The purpose was to maintain the HWW fluctuating specificity and to study the influence of the initial concentration on the sMBRe performances. Considering the high-identified concentrations in 5-FU, the applied doping is important (Table 4). It should be noted that these drug supplements are however too weak to influence the biomass performances. IF and CP doping are far below the concentrations contained in the sampled HWW. CD doping was overestimated but its whole concentration in the feed remains low versus other drugs. SM was overestimated too.

The permeate sample is collected after a minimum time equal to the HRT of sMBRe in order to meet the sampling representability. The evolution of the drug reductions selected by the sMBRe are presented on Fig. 12. The reductions are calculated from the drug concentrations in feed (sampled HWW + doping) and in the permeate. Just like the purification of conventional pollution, the drug removal via hospital sMBRe was submitted to various fluctuations during the experimental campaign. The removal of the 4 drugs increased until day 115 except day 98 with $22 \%$ removed IF. This low apparent removal of IF at that time corresponds to its maximum concentration identified in HWW (8.32 $\mathrm{mg} \mathrm{L}^{-1}$ with doping). A $1.83 \mathrm{mg} \mathrm{L}^{-1}$ difference between feed and permeate is however noticed and indicates that the sMBRe proved effective. With such a considerable concentration, ifosfamide is liable to have an inhibition because its removal no longer depends only on the initial concentration. During this period, SM is still removed over $96 \%$, CD and CP over $67 \%$.

An excellent overall removal of the 4 drugs was obtained on day
115. CP was the less removed molecule with $89 \%$. The analysis of the reactor supernatant at that time showed that the retention rate by the membrane of codeine, cyclophosphamide, ifosfamide and sulfamethoxazole in the sMBRe supernatant was 81, 86, 91 and 95\% respectively (Table 3). The analysis of both other supernatant samples on the 128th and 143rd days confirmed a drug retention by the hollow fiber membranes (rather limited).

The results are very surprising since all the studies agree on the fact that microfiltration or ultrafiltration membranes used in MBRs cannot retain drug molecules because they are very small, generally around 200-300 Da. They are at least 100-1000 times smaller than the membrane cutoff $[29,55]$. In an eMBR pilot, Delgado and Seira $[14,54]$ did not observe any retention of cyclophosphamide by the ceramic membrane with a $0.2 \mu \mathrm{m}$ MWCO. This MWCO, which corresponds to $400 \mathrm{kDa}$ approximately, is 4 times higher to the $100 \mathrm{kDa}$ hollow fiber one used during this experimental campaign. Recently, Zaviska et al. [67] identified over $60 \% \mathrm{CP}$ retention in a MBR-NF when the fouling of the nanofiltration membrane with a $600 \mathrm{Da}$ cutoff has become more important.

The results show that fouling of hollow fiber membranes with a $100 \mathrm{kDa}$ MWCO 330-400 times bigger than the size of the selected drug molecules, can be an important drug retention mechanism in the sMBRe, even major in a serious fouling. However, fouling cannot explain alone the results obtained since the drug retention on the 143rd day with an almost new membrane proved more significant than the one on the 128th day with a moderate fouled membrane. The mixed liquor properties, the biomass physiological state and the fouling nature could have an important role in the retention of the selected drugs.

The study of the COD and ammonium removal in the supernatant as well as $\mathrm{F} / \mathrm{M}$ ratio in COD and ammonium on times corresponding to the available data on drug concentrations in the supernatant outline a difference of behavior according to drug molecules (Table 5). Indeed, the reduction in the reactor by $78 \%$ for CD and $95 \%$ for SM on the 115 th day no longer presents an inhibition of heterotrophic bacteria. It is indicated by a reduction of $\mathrm{COD}_{\mathrm{S}}$ less than $10 \%$ and low $\mathrm{COD}$ and ammonium concentrations of HWW. The major quantity of metabolized SM shows that the biotransformation via co-metabolism has not been limited by low COD and ammonium contents. The result also shows the key role of autotrophic bacteria on the SM and CD removal. Conversely, the removal in the reactor of about $20 \% \mathrm{CP}$ and IF appears substantially altered by this inhibition of heterotrophs and/or the very low COD and ammonium contents on the 115th day. Their biological removal lies in fact between 31 and $38 \%$ for the 2 other dates coinciding with a better $\mathrm{COD}_{\mathrm{S}}$ reduction and concentrations of COD and ammonium respectively 2.5 and 6 times higher than on the 115th day. The quantity of substrate available could therefore play a major role on the

Table 4

Total concentrations (OWW + doping) of selected pharmaceuticals in the feeding source of the sMBRe.

\begin{tabular}{|c|c|c|c|c|c|c|c|c|c|c|c|c|}
\hline \multirow{3}{*}{$\begin{array}{c}\text { Molecule } \\
\text { CD }\end{array}$} & \multicolumn{12}{|c|}{ Day } \\
\hline & \multicolumn{2}{|c|}{70} & \multicolumn{3}{|c|}{84} & \multicolumn{2}{|c|}{98} & & \multicolumn{2}{|c|}{115} & \multicolumn{2}{|c|}{128} \\
\hline & 180 & 100 & & 391 & 96 & 523 & 96 & & 375 & 100 & 0 & 0 \\
\hline CP & 1195 & 84 & & 500 & 100 & 0 & 0 & & 687 & 0 & 450 & 100 \\
\hline IF & 1828 & 82 & & 900 & 100 & 8320 & 18 & & 1030 & 97 & 900 & 100 \\
\hline SM & 58 & 0 & & 1290 & 100 & 1180 & 100 & & 1190 & 42 & 2000 & 100 \\
\hline \multirow[t]{2}{*}{ Molecule } & \multicolumn{12}{|c|}{ Day } \\
\hline & \multicolumn{3}{|c|}{143} & & \multicolumn{2}{|c|}{158} & & & 165 & & \multicolumn{2}{|c|}{171} \\
\hline $\mathrm{CD}$ & 375 & & 100 & & 0 & 0 & & 19 & & & 47 & 0 \\
\hline $\mathrm{CP}$ & 609 & & 74 & & 272 & 0 & & 203 & & & 388 & 64 \\
\hline $\mathrm{IF}$ & 1620 & & 62 & & 3486 & 26 & & 517 & & & 965 & 26 \\
\hline SM & 2500 & & 100 & & 1000 & 100 & & 729 & & & 1710 & 58 \\
\hline
\end{tabular}

Concentrations units are in $\mu \mathrm{L} \mathrm{L}^{-1}$. The numbers in italics indicate the percentage due to doping in relation to its total concentration in the feeding source. 

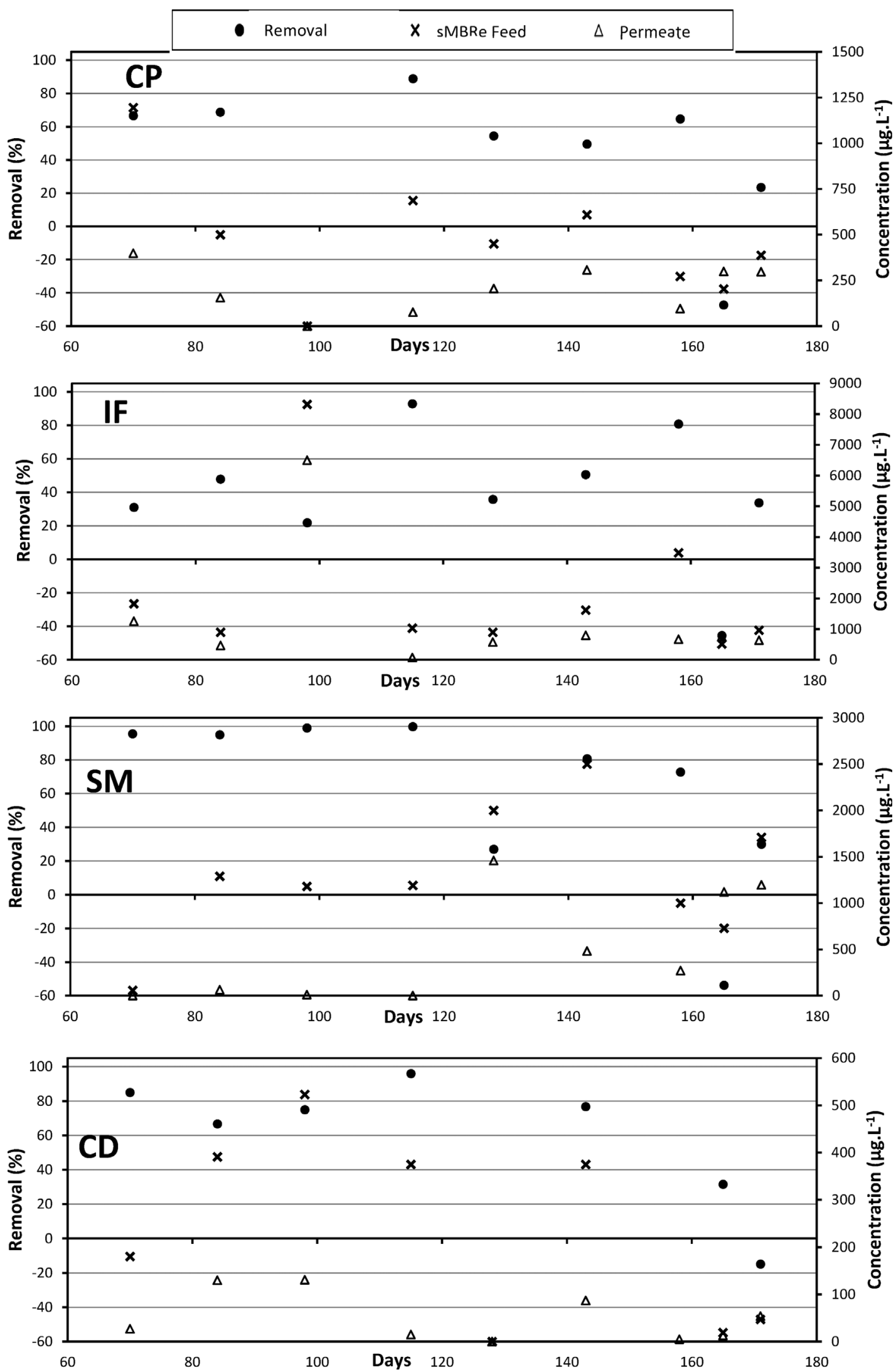

Fig. 12. Evolution of the selected pharmaceuticals removals by sMBRe.

biotransformation of both molecules. It should however be noted that the excellent removal of ammonium on the 143rd day is not related to a removal of SM as significant in the reactor. Again, it demonstrates the great complexity of interaction of the parameters, which influence the drug removal. The drug retention by the membrane and its fouling does not allow the analysis of the influence of COD and ammonium 
Table 5

Performances of sMBRe for the removal of COD in supernatant and ammonia for the selected dates.

\begin{tabular}{|c|c|c|c|c|c|c|c|}
\hline Date & Molecule & $\begin{array}{l}\text { Reactor removal } \\
\text { efficiency (\%) }\end{array}$ & $\begin{array}{c}\text { Total removal efficiency } \\
(\%)\end{array}$ & $\begin{array}{c}\mathrm{COD}_{\mathrm{S}} \text { removal efficiency } \\
(\%)\end{array}$ & $\begin{array}{c}\mathrm{N}-\mathrm{NH}_{4}{ }^{+} \text {Removal } \\
\text { efficiency (\%) }\end{array}$ & $\begin{array}{l}\mathrm{DCO}_{\text {Oww }} \\
\left(\mathrm{mg} \mathrm{L}^{-1}\right)\end{array}$ & $\begin{array}{l}\mathrm{N}-\mathrm{NH}_{4}^{+}{ }^{+}+W \mathrm{~W} \\
\left(\mathrm{mg} \mathrm{L}^{-1}\right)\end{array}$ \\
\hline \multirow[t]{4}{*}{ 115th day } & $\mathrm{CD}$ & 78.7 & 96 & 10 & 98 & 148 & 8.9 \\
\hline & $\mathrm{CP}$ & 19.7 & 88.9 & & & & \\
\hline & IF & 21.5 & 92.9 & & & & \\
\hline & SM & 95.2 & 99.7 & & & & \\
\hline \multirow[t]{4}{*}{ 128th day } & $\mathrm{CD}$ & - & - & 76 & 79 & 409.6 & 61.7 \\
\hline & $\mathrm{CP}$ & 38.2 & 54.4 & & & & \\
\hline & IF & 31.8 & 35.8 & & & & \\
\hline & SM & -8.5 & 27 & & & & \\
\hline \multirow[t]{4}{*}{ 143rd day } & $\mathrm{CD}$ & 71.2 & 76.8 & 69 & 96 & 399.6 & 50 \\
\hline & $\mathrm{CP}$ & 36.6 & 49.6 & & & & \\
\hline & IF & 37.7 & 50.6 & & & & \\
\hline & SM & 38.8 & 80.7 & & & & \\
\hline
\end{tabular}

concentrations in HWW on the removal of the selected drugs for the periods when data on the supernatant are not available.

An overall drop of performances to remove the selected drugs has been noticed after the 115th day. This drop could be the result of a weaker membrane fouling after the sampling dates. It could also be the result of the biomass affected by the various reloading involving a partial loss of the acclimation advantages on the degradation of drug molecules. The latter assumption could be rejected for CP and IF in terms of reduction in the reactor far higher on the 128th and 143rd days than on the 115th day. So, the drop in the overall removal could be partly the result of the sMBRe hospital operation at less important fouling levels.

Sulfamethoxazole and codeine are the best removed molecules by sMBRe with respectively 75 and $72 \%$ mean elimination (Table 6). The removal of both anticancers proves less with $60 \%$ on average for cyclophosphamide and $49 \%$ for ifosfamide. The interest of the representation of the reduction by the sMBRe according to the concentration of the initial feeding is limited due to the retention by the membrane and the fouling of the selected drugs distorting the actual concentrations of drugs upstream of the membrane.

The CD elimination recorded during this study meets the order of magnitude of the best performances in the literature $[65,51,16]$. Note that these performances were performed for UWW with codeine concentrations lower than $3 \log$ (in comparison with this study) and that the 2 best removals are obtained via MBR. A lot of data are available in the literature about the SM removal. Apart from some studies about conventional processes with activated sludge for which low reductions were identified $[5,60,31]$, the SM removal is generally higher or around $70 \%$. The study is close to the present work, because it is about the treatment on the spot of overall HWW via MBR [34] and shows a SM reduction very low by $7 \%$ marked by a large variability with an initial concentration to $3.476 \pm 4.588 \mu \mathrm{g} \mathrm{L}{ }^{-1}$ far less than the one noticed in the present study. The best performances obtained with an average SM removal of $75.0 \%$ show that it is possible to remove the drug directly on

Table 6

Synthesis of the performances of the sMBRe on the removal of the selected pharmaceuticals.

\begin{tabular}{cccc}
\hline \multirow{2}{*}{ Molecules } & \multicolumn{3}{c}{ Removal efficiency (\%) } \\
\cline { 2 - 4 } & Min & Max & Average \\
\hline Codeine & $31.6(165)$ & $96.0(115)$ & 71.9 \\
Cyclophosphamide & $23.5(171)$ & $88.9(115)$ & 59.5 \\
Ifosfamide & $21.9(98)$ & $92.9(115)$ & 49.3 \\
Sulfamethoxazole & $27.0(128)$ & $99.7(115)$ & 75.0 \\
\hline
\end{tabular}

Values are in \%.

The date corresponding to the minimal or maximal removal is written in blankets. The negative removals were not taken into account as it results of a membrane replacement. the site at a high level. It should be noticed that a part of this improvement towards the study [34] could come from the doping method of HWW by adding SM only without the human metabolite being able to recombine SM during the biological treatment.

The average 59.5\% CP removal obtained during this study is similar to Seira's [54], which rely on a sampled UWW doping too but for far more important input concentrations. The only study treating on site hospital effluents via MBR has a CP removal less than 20\% [34]. It is noteworthy that their study focused on the overall hospital HWW resulting in an average input CP concentration of $0.161 \pm 0.026 \mu \mathrm{g} \mathrm{L}^{-1}$ consequently 3-6 log weaker than the present study. Zaviska et al. [67] also observed a CP retention by their NF membrane up to $60 \%$ allowing a maximum removal of $80 \%$ via their MBR-NF. So, in this study the serious membrane fouling on the 115th day had the best CP removal listed to $88.9 \%$ for a MBR treating an actual effluent on the site. There is no observation in the literature of IF removal via conventional activated sludge WWTP. The average $49.3 \%$ removal in this study is the first positive result about the removal of the most used anticancer in the oncology ward of the study. Average identified purification efficiency on drugs agrees with the literature for $\mathrm{CD}$, SM and $\mathrm{CP}$. The performances were achieved by treating HWW whose inhibitory effects on the bacterial growth and on the regularity of the purification efficiency were demonstrated. Besides, the hospital sMBRe could degrade these drugs at high concentrations, of several logs in some cases towards the previous studies identified in the literature. The results justify both the treatment strategy on the issuing site for treating a highly concentrated drug effluent and the choice of the MBR process to both improve the biological removal of the selected drugs and physically retain a significant fraction of drug residual concentration by the membrane in case of serious fouling.

\section{Conclusion}

The follow-up of purification efficiency of the eMBR on drugs has been carried out on the three most consumed anticancer drugs: ifosfamide (IF), fluorouracil (5-FU) and cyclophosphamide (CP); the codeine painkiller (CD) and the sulfamethoxazole antibiotic (SM) were added to this study. The sampled oncological ward wastewater (HWW) are outlined by a high variability of composition, some concentrations measured in $6.82 \mathrm{mg}_{\mathrm{IF}} . \mathrm{L}^{-1}, \quad 1.28 \mathrm{mg}_{5-\mathrm{Fu}} . \mathrm{L}^{-1}, \quad 687 \mu \mathrm{g}_{\mathrm{CP}} . \mathrm{L}^{-1}$ and $710 \mu \mathrm{g}_{\mathrm{SM}} . \mathrm{L}^{-1}$ are the highest concentrations in the literature with an order of magnitude greater than 2 log compared with overall hospital effluents. These composition fluctuations have not made acclimation of activated sludge from a municipal WWTP easy in the MBR pilot. A low biomass growth was observed after 160 days with the eMBR whereas there was an almost continuous loss for acclimation based on sMBRe. However, during acclimation with sMBRe, a significant bacterial growth obtained at the end of the campaign indicates that inhibition from HWW on the biomass reproductive abilities is not irreversible and 
that a growth can occur whenever possible. The ideal conditions determined would include (i) the absence of surfactants in HWW. (ii) A C/ $\mathrm{N}$ ratio of HWW less than 30 , which is the critical value as a decrease in the COD removal occurred systematically beyond. (iii) The application of a F/M in COD relatively high, probably higher than $0.20 \mathrm{~kg}_{\mathrm{COD}} \mathrm{kg}_{\mathrm{Vss}}{ }^{-1} \cdot \mathrm{d}^{-1}$ seems necessary. The inhibition exerted by HWW would be selective for independent of the applied F/M. A strong $\mathrm{F} / \mathrm{M}$ would allow not impacted bacterial species to assimilate the substrate easily biodegradable of HWW to offset or exceed the losses on sensitive species. Despite the complexity of HWW, purification yields above $90 \%$ on COD and ammonium have been reached gradually, which demonstrates that inhibition is not irreversible. The application of a strong F/M gave higher purification yields. The biggest substrate quantity available easily biodegradable could have helped the biomass to compensate for the losses induced by the HWW toxicity but also to degrade a part of the recalcitrant compounds via co-metabolism. The denitrification reaction seems however inhibited permanently. The origin of the malfunction seems to come from surfactants used in large amounts in hospital services. In terms of performance, 5-FU was eliminated almost systematically over $90 \%$. The molecule can easily be removed as confirmed by sludge performances of the WWTP. The removal of four other drugs experienced a lot of fluctuations due to HWW effects on the biomass and by their retention by the membrane and it's fouling, distorting the actual concentrations upstream of the membrane. Removals in the sMBRe supernatant show that SM and CD can be significantly eliminated biologically, respectively to 79 and $95 \%$ while eliminating IF and $\mathrm{CP}$ in the reactor appears more moderate since it does not exceed $40 \%$. The high membrane fouling reaches an apparent removal above or equal to $89 \%$ of the whole selected drugs. This phenomenon had never been outlined in the literature apart from the obvious studies including membranes with cutoff below the studied $100 \mathrm{kDa}$ hollow fibers. Activated sludge developed in the MBR pilot showed great abilities to adapt to drugs contained in HWW, especially for anticancer CP and IF. This finding is supported by the conservation of the purification capacities of the biomass in the presence of drug cocktail, by acquiring a pronounced antibiotic resistance and especially by the creation of biotransformation capacities on selected drugs.

\section{Acknowledgements}

The authors acknowledge the Ianesco laboratory (Institut d'Analyses et d'Essais en Chimie de l'Ouest, Poitiers, France) for their help.

\section{References}

[1] A. Al-Ahmad, F. Daschner, K. Kümmerer, Biodegradability of cefotiam, cipro floxacin, meropenem, penicillin $\mathrm{G}$, and sulfamethoxazole and inhibition of waste water bacteria, Arch. Environ. Contam. Toxicol. 37 (2) (1999) 158-163.

[2] A. Barrios-Martinez, E. Barbot, B. Marrot, P. Moulin, N. Roche, Degradation of phenol-containing effluents by MBR, J. Membrane Sci. 288 (2006) 288-296.

[3] J.-P. Besse, J.-F. Latour, J. Garric, Anticancer drugs in surface waters: what can we say about the occurrence and environmental significance of cytotoxic, cytostatic and endocrine therapy drugs? Environ. Int. 39 (1) (2012) 73-86.

[4] M. Bernhard, J. Müller, T. Knepper, Biodegradation of persistent polar pollutants in wastewater: comparison of an optimised lab-scale membrane bioreactor and activated sludge treatment, Water Res. 40 (2006) 3419-3428.

[5] K. Brown, J. Kulis, B. Thomson, T. Chapman, D. Mawhinney, Occurrence of Antibiotics in Hospital, Residential, and Dairy Effluent, Municipal Wastewater, and the Rio, (2006).

[6] CASFM, Recommandations 2013, (2013).

[7] Y. Chen, G. Yu, Q. Cao, H. Zhang, Q. Lin, Y. Hong, Occurrence and environmental implications of pharmaceuticals in Chinese municipal sewage sludge, Chemosphere 93 (9) (2013) 1765-1772.

[8] M. Clara, N. Kreuzinger, B. Strenn, O. Gans, H. Kroiss, The solids retention time-a suitable design parameter to evaluate the capacity of wastewater treatment plants to remove micropollutants, Water Res. 39 (2005) 97-106.

[9] L. Clouzot, Etude du bioréacteur à membrane pour l'élimination de l'hormone synthétique $17 \alpha$-éthinylestradiol. Thèse de doctorat, Université Paul Cézanne d'AixMarseille, 2009.

[10] L. Clouzot, P. Doumenq, N. Roche, B. Marrot, Kinetic parameters for 17a-ethinylestradiol removal by nitrifying activated sludge developed in a membrane bioreactor, Bioresour. Technol. 101 (2010) 6425-6431.

[11] L. Clouzot, N. Roche, B. Marrot, Effect of membrane bioreactor configurations on sludge structure and microbial activity, Bioresour. Technol. 102 (2) (2011) 975-981.

[12] V. Cunningham, S. Binks, M. Olson, Human health risk assessment from the presence of human pharmaceuticals in the aquatic environment, Regul. Toxicol. Pharm. 53 (2009) 39-45.

[13] H. De Wever, S. Weiss, J. Reemtsma Vereecken, J. Müller, T. Knepper, O. Rörden, S. Gonzalez, D. Barcelo, M. Hernando, Comparison of sulfonated and other micropollutants removal in membrane bioreactor and conventional wastewater treatment, Water Res. 41 (2007) 935-945.

[14] L. Delgado, Bioréacteur à membrane externe pour le traitement d'effluents contenant des médicaments anticancéreux: élimination et influence du cyclophosphamide et de ses principaux métabolites sur le procédé. Thèse de doctorat, INP Toulouse, 2009.

[15] N. Deloffre-Bonnamour, Les rejets des établissements de santé: des effluents liquides aux déchets solides. Mémoire de maîtrise, Université Claude Bernard, Lyon, 1995.

[16] D. Dolar, M. Gros, S. Rodriguez-Mozaz, J. Moreno, J. Comas, I. Rodriguez-Roda, D. Barcelo, Removal of emerging contaminants from municipal wastewater with an integrated membrane system, MBR-RO, J. Hazard. Mater. (2012) 64-69.

[17] E. Emmanuel, Évaluation des risques sanitaires et écotoxicologiques liés aux effluents hospitaliers. Thèse de doctorat, INSA de Lyon, 2004.

[18] E. Emmanuel, Y. Perrodin, G. Keck, J.M. Blanchard, P. et Vermande, Ecotoxicological risk assessment of hospital wastewater: a proposed framework for raw effluents discharging into urban sewer network, J. Hazard. Mater. 117 (1) (2005) 1-11.

[19] A. Foster, Occurrence and Fate of Endocrine Disruptors Through the San Marcos Wastewater Treatment Plant. Thèse de Master, San Marcos (Texas, Etats-Unis), 2007.

[20] M. Fram, K. Belitz, Occurrence and concentrations of pharmaceutical compounds in groundwater used for public drinking-water supply in California, Sci. Total Environ. 409 (18) (2011) 3409-3417.

[21] J. Gagnaire, Couplage de procédés appliqué au traitement d'un effluent de compostage. Thèse de doctorat, Université Paul Cézanne d'Aix-Marseille, 2010.

[22] C. Gomez-Canela, N. Cortes-Francisco, C. Pujol, F. Ventura, S. Lacorte, J. Caixach, Occurrence of cyclophosphamide and epirubicin in wastewaters by direct injection analysis-liquid chromatography-high-resolution mass spectrometry, Environ. Sci. Pollut. Res. Int. 19 (8) (2012) 3210-3218.

[23] A. Grasmick, C. Cabassu, M. Spérandio, C. Wisniewski, Bioréacteurs à membranes et traitement des eaux usées, Les techniques de l'ingénieur (2007) W4140.

[24] E. Gullberg, S. Cao, O.G. Berg, C. Ilback, L. Sandergren, D. Hughes, Selection of resistant bacteria at very low antibiotic concentrations, PLoS Pathog. (2011).

[25] P. Hamon, P. Moulin, L. Ercolei, B. Marrot, Performance of a biomass adapted to oncological ward wastewater vs. biomass from municipal WWTP on the removal of pharmaceutical molecules, Water Res. 128 (2018) 193-205.

[26] S. Hann, Æ.Zs. Stefanka, Æ.K. Lenz, Æ.G. Stingeder, Novel separation method for highly sensitive speciation of cancerostatic platinum compounds by HPLC-ICP-MS, Anal. Bioanal. Chem. 381 (2005) 405-412.

[27] P. Hartemann, A. Hautemaniere, M. Joyeux, La problématique des effluents hos pitaliers, Hygiène 13 (5) (2005) 369-374.

[28] L. Johnson, D. Lomax, M. Myers, O. Olson, S. Sol, S. O'Neill, J. West, T. Collier, Xenoestrogen exposure and effects in English sole (Parophrys vetulus) from Puget Sound, WA, Aquat. Toxicol. 88 (2008) 29-38.

[29] A. Joss, E. Keller, A. Alder, A. Göbel, C. McArdell, T. Ternes, H. Siegrist, Removal of pharmaceuticals and fragrances in biological wastewater treatment, Water Res. 39 (2005) 3139-3152.

[30] T. Junker, R. Alexy, T. Knacker, K. Kümmerer, Biodegradability of 14C-Labeled antibiotics in a modified laboratory scale sewage treatment plant at environmentally relevant concentrations, Environ. Sci. Technol. 40 (2006) 318-324.

[31] B. Kasprzyk-Hordern, R. Dinsdale, A. Guwy, The removal of pharmaceuticals, personal care products, endocrine disruptors and illicit drugs during wastewater treatment and its impact on the quality of receiving waters, Water Res. 43 (2009) $363-380$.

[32] K. Kimura, H. Hara, Y. Watanabe, Removal of pharmaceutical compounds by submerged membrane bioreactors (MBRs), Desalination 178 (2005) 135-140.

[33] T. Kosjek, E. Heath, Occurrence, fate and determination of cytostatic pharmaceuticals in the environment, Trends Anal. Chem. 30 (7) (2011) 1065-1087.

[34] L. Kovalova, H. Siegrist, H. Singer, A. Wittmer, C. McArdell, Hospital wastewater treatment by membrane bioreactor: performance and efficiency for organic micropollutant elimination, Environ. Sci. Technol. 46 (2012) 1536-1545.

[35] B. Kraigher, I. Mandic-Mulec, Nitrification activity and community structure of nitriteoxidizing bacteria in the bioreactors operated with addition of pharmaceuticals, J. Hazard. Mater. 188 (2011) 78-84.

[36] K. Kümmerer, T. Steger-Hartmann, M. Meyer, Biodegradability of the anti-tumour agent ifosfamide and its occurrence in hospital effluents and communal sewage, Water Res. 31 (11) (1997) 2705-2710.

[37] K. Kummerer, A. Al-Ahmad, Biodegradability of the anti-tumor agents 5-fluorouracil, cytarabine, and gemcitabine: impact of the chemical structure and synergistic toxicity with hospital effluent, Acta Hydrochim. Hydrobiol. 25 (4) (1997) 166-172.

[38] K. Kummerer, E. Helmers, Hospital effluents as a source of platinum for the environment, Sci. Total Environ. 193 (1997) 179-184.

[39] K. Kümmerer, The presence of pharmaceuticals in the environment due to human use-present knowledge and future challenges, J. Environ. Manage. 90 (8) (2009) 2354-2366.

[40] K. Li, A. Yediler, M. Yang, S. Schulte-Hostede, M. Wong, Ozonation of 
oxytetracycline and toxicological assessment of its oxidation by-products, Chemosphere 72 (2008) 473-478.

[41] S. Mahnik, K. Lenz, N. Weissenbacher, R. Mader, M. Fuerhacker, Fate of 5-fluorouracil, doxorubicin, epirubicin, and daunorubicin in hospital wastewater and their elimination by activated sludge and treatment in a membrane-bio-reactor system, Chemosphere 66 (2007) 30-37.

[42] I. Michael, L. Rizzo, C.S. McArdell, C.M. Manaia, C. Merlin, T. Schwartz, C. Dagot, D. Fatta-Kassinos, Urban wastewater treatment plants as hotspots for the release of antibiotics in the environment: a review, Water Res. 47 (2013) 957-995.

[43] C. Miège, M. Favier, C. Brosse, J.P. Canler, M. Coquery, Occurrence of betablockers in effluents of wastewater treatment plants from the Lyon area (France) and risk assessment for the downstream rivers, Talanta 70 (4) (2006) 739-744.

[44] J. Oh, J. Silverstein, Oxygen inhibition of activated sludge, Water Res. 33 (8) (1999) 1925-1937.

[45] F. Orias, Y. Perrodin, Characterisaiton of the ecotoxicity of hospital effluents: a review, Sci. Total Environ. 454-455 (2013) 250-276.

[46] X. Peng, Z. Wang, W. Kuang, J. Tan, K. Li, A preliminary study on the occurrence and behavior of sulfonamides, ofloxacin and chloramphenicol antimicrobials in wastewaters of two sewage treatment plants in Guangzhou, China, Sci. Total Environ. 371 (1-3) (2006) 314-322.

[47] M. Petrović, B. Škrbić, J. Živančev, L. Ferrando-Climent, D. Barcelo, Determination of 81 pharmaceutical drugs by high performance liquid chromatography coupled to mass spectrometry with hybrid triple quadrupole-linear ion trap in different types of water in Serbia, Sci. Total Environ. 468-469 (2014) 415-428.

[48] N. Prado, J. Ochoa, A. Amrane, Biodegradation by activated sludge and toxicity of tetracycline into a semi-industrial membrane bioreactor, Bioresour. Technol. 100 (2009) 3769-3774.

[49] J. Radjenovic, M. Petrovic, D. Barcelo, Advanced mass spectrometric methods applied to the study of fate and removal of pharmaceuticals in wastewater treatment, Trends Anal. Chem. 26 (11) (2007) 1132-1144.

[50] J. Radjenovic, M. Petrovic, D. Barcelo, Fate and distribution of pharmaceuticals in wastewater and sewage sludge of the conventional activated sludge (CAS) and advanced membrane bioreactor (MBR) treatment, Water Res. 43 (2009) 831-841.

[51] R. Rosal, A. Rodriguez, J. Perdigon-Melon, A. Petre, E. Garcia-Calvo, M. Gomez A. Agüera, A. Fernandez-Alba, Occurrence of emerging pollutants in urban wastewater and their removal through biological treatment followed by ozonation, Water Res. 44 (2010) 578-588.

[52] L. Santos, M. Gros, S. Rodriguez-Mozaz, C. Delerue-Matos, A. Pena, D. Barcelo, M. Montenegro, Contribution of hospital effluents to the load of pharmaceuticals in urban wastewaters: identification of ecologically relevant pharmaceuticals, Sci. Total Environ. 461-462 (2013) 302-316.

[53] K. Seifert, F. Domka, Inhibiting effect of surfactants and heavy metal ions on the denitrification process, Pol. J. Environ. Stud. 14 (1) (2004) 87-93.

[54] J. Seira, Rôle de la sorption et de la biodégradation dans l'élimination de micropolluants par des procédés d'épuration biologique: application aux molécules anticancéreuses traitées par bioréacteur à membrane. Thèse de doctorat, Université de Toulouse, 2013.
[55] J. Sipma, B. Osuna, N. Collado, H. Monclus, G. Ferrero, J. Comas, I. RodriguezRoda, Comparison of removal of pharmaceuticals in MBR and activated sludge systems, Desalination 250 (2) (2010) 653-659.

[56] T. Stalder, Implication des effluents d'activités hospitalières et de la filière carnée sur la dissémination de l'antibiorésistance: dynamique des intégrons de l'émission au rejet. Thèse de doctorat, Université de Limoges, 2012.

[57] Steger-Hartmann, K. Kümmerer, A. Hartmann, Biological degradation of cyclophosphamide and its occurrence in sewage water, Ecotoxicol. Environ. Saf. 36 (1997) 174-179.

[58] J. Straub, Combined environmental risk assessment for 5-fluorouracil and capecitabine in Europe, Integr. Environ. Assess. Manag. 6 (2010) 540-566.

[59] J. Tambosi, R. Sena, M. Favier, W. Gebhardt, H. José, H. Schröder, R. Moreira, Removal of pharmaceutical compounds in membrane bioreactors (MBR) applying submerged membranes, Desalination 261 (2010) 148-156.

[60] T. Ternes, M. Bonerz, N. Herrmann, B. Teiser, H. Andersen, Irrigation of treated wastewater in Braunschweig, Germany: an option to remove pharmaceuticals and musk fragrances, Chemosphere 66 (2007) 894-904.

[61] P. Verlicchi, A. Galetti, M. Petrovic, D. Barcelo, Hospitals effluents as a source of emerging pollutants: an overview of micropollutants and sustainable treatment options, J. Hydrol. 389 (3-4) (2010) 416-428.

[62] P. Verlicchi, M. Al Aukidy, A. Galletti, M. Petrovic, D. Barcelo, Hospital effluent: investigation of the concentrations and distribution of pharmaceuticals and environmental risk assessment, Sci. Total Environ. 430 (2012) 109-118.

[63] A. Watkinson, E. Murby, S. Costanzo, Removal of antibiotics in conventional and advanced wastewater treatment: implications for environmental discharge and wastewater recycling, Water Res. 41 (2007) 4164-4176.

[64] A. Watkinson, E. Murby, D. Kolpin, S. Costanzo, The occurrence of antibiotics in an urban watershed: from wastewater to drinking water, Sci. Total Environ. 407 (2009) 2711-2723.

[65] A. Wick, G. Fink, A. Joss, H. Siegrist, T. Ternes, Fate of beta blockers and psychoactive drugs in conventional wastewater treatment, Water Res. 43 (2009) 1060-1074.

[66] J. Yin, B. Shao, J. Zhang, K. Li, A preliminary study on the occurrence of cytostatic drugs in hospital effluents in Beijing, China, Bull. Environ. Contam. Toxicol. 84 (2010) 39-45.

[67] F. Zaviska, P. Drogui, A. Grasmick, A. Azais, M. Héran, Nanofiltration membrane bioreactor for removing pharmaceutical compounds, J. Membr. Sci. 429 (2013) $121-129$.

[68] D. Zhang, R. Gesberg, W. Ng, S. Tan, Removal of pharmaceuticas and personal care products in aquatic plant-based systems: a review, Environ. Pollut. 184 (2014) 620-639.

[69] R. Zounkova, L. Kovalova, L. Blaha, W. Dott, Ecotoxicity and genotoxicity of assessment of cytoyoxic antineoplastic drugs and their metabolites, Chemosphere 81 (2010) 253-260.

[70] E. Zuccato, S. Castiglioni, R. Bagnati, M. Melis, R. Fanelli, Source, occurrence and fate of antibiotics in the Italian aquatic environment, J. Hazard. Mater. 179 (1-3) (2010) 1042-1048. 